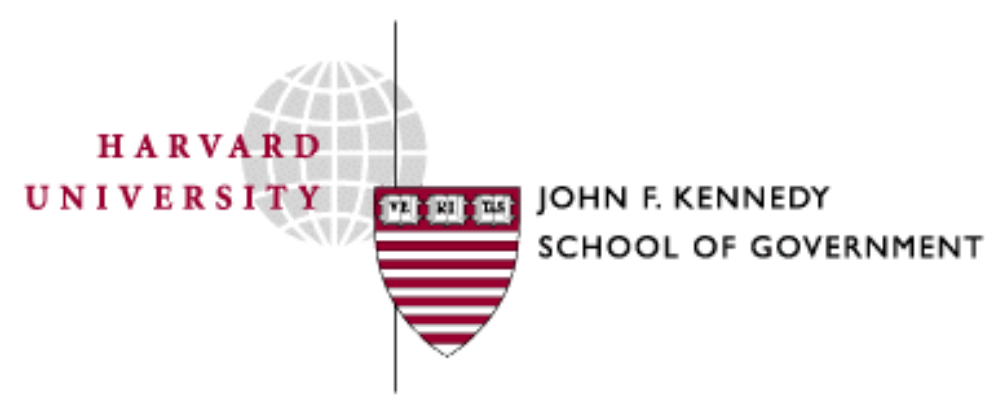

Faculty Research Working Papers Series

\author{
South Africa's Export Predicament \\ Ricardo Hausmann and Bailey Klinger \\ John F. Kennedy School of Government - Harvard University
}

September 2006

RWP06-040

The views expressed in the KSG Faculty Research Working Paper Series are those of the author(s) and do not necessarily reflect those of the John F. Kennedy School of Government or Harvard University. Copyright belongs to the author(s). Papers may be downloaded for personal use only. 


\title{
South Africa's Export Predicament
}

\author{
Ricardo Hausmann and Bailey Klinger
}

CID Working Paper No. 129

August 2006

(C) Copyright 2006 Ricardo Hausmann, Bailey Klinger, and the President and Fellows of Harvard College

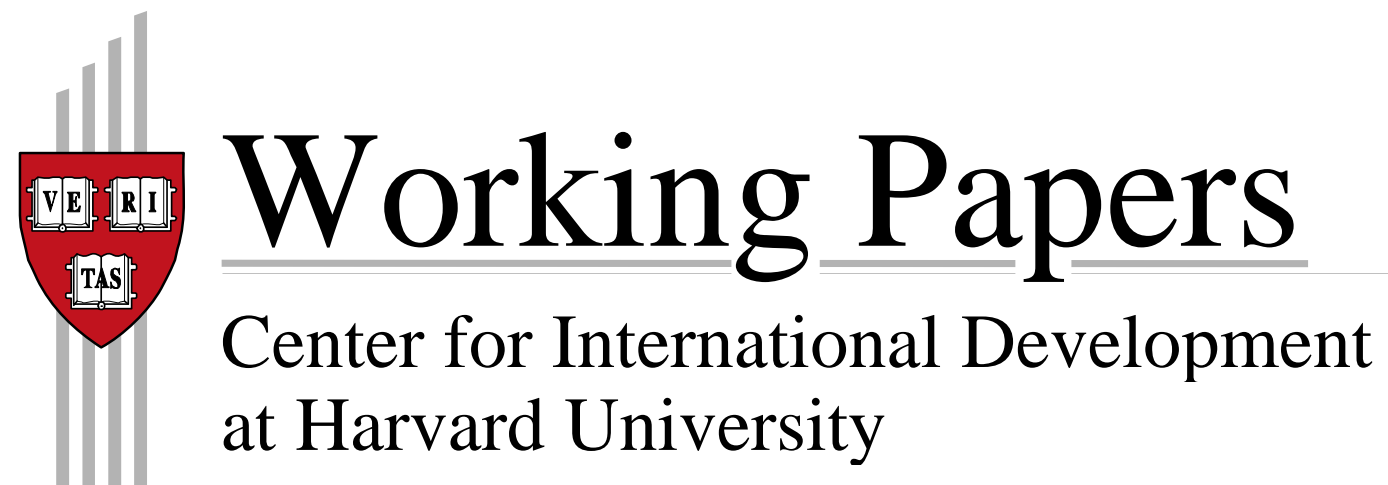




\title{
South Africa's Export Predicament
}

Ricardo Hausmann and Bailey Klinger

DRAFT, August 2006

\begin{abstract}
This paper explores export performance in South Africa over the past 50 years, and concludes that a lagging process of structural transformation is part of the explanation for stagnant exports per capita. Slow structural transformation in South Africa is found to be a consequence of the peripheral nature of South Africa's productive capabilities. We apply new tools to evaluate South Africa's future prospects for structural transformation, as well as to explore the sectoral priorities of the DTI's draft industrial strategy. We then discuss policy conclusions, advocating an 'open-architecture' industrial policy where the methods applied herein are but one tool to screen private sector requests for sector-specific coordination and public goods.
\end{abstract}

Keywords: South Africa, Structural Transformation

JEL Codes: 055, F19, O14, O33, O40

This paper is part of the South Africa Growth Initiative. The Center for International Development has convened an international panel of economists and international experts from Harvard University, the Massachusetts Institute of Technology, the University of Michigan, and other institutions to work with South African economists to study that country's constraints to and opportunities for accelerated growth. This project is an initiative of the National Treasury of the Republic of South Africa within the government's Accelerated and Shared Growth Initiative (ASGI-SA), which seeks to consolidate the gains of post-transition economic stability and accelerate growth in order to create employment and improve the livelihoods of all South Africans.

Valuable comments were provided by numerous workshop participants at Harvard and in South Africa, and in particular by Lawrence Edwards, Johannes Fedderke, Alan Hirsch, David Kaplan, Nimrod Zalk, and the entire CID team (in particular Philippe Aghion, Robert Lawrence, Dani Rodrik, Federico Sturzenegger, and Roberto Rigobon). All errors and omissions are our own.

Comments: ricardo_hausmann@harvard.edu \& bailey_klinger@ksgphd.harvard.edu 


\section{Table of Contents}

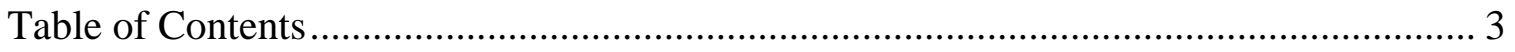

Section 1: Does South Africa face an Export Predicament?............................................. 4

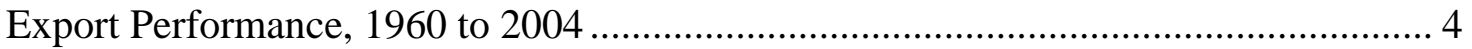

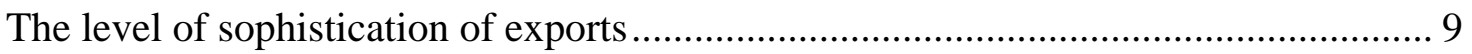

Section 2: Structural Transformation in South Africa ................................................. 13

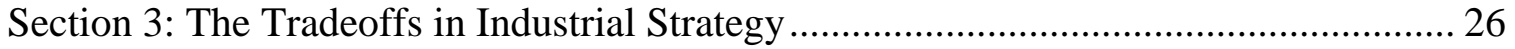

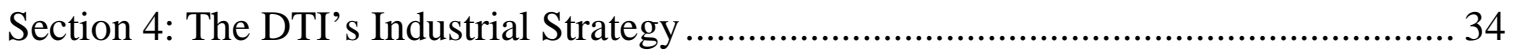

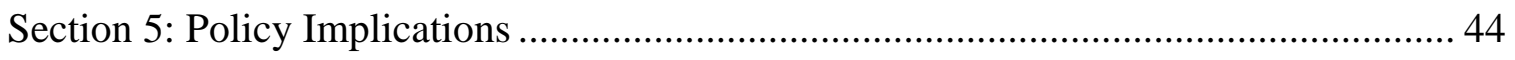

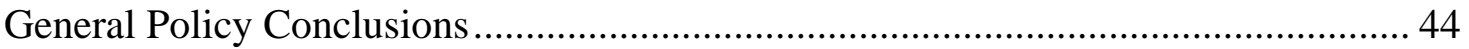

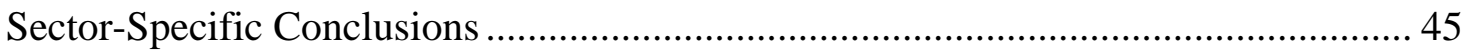

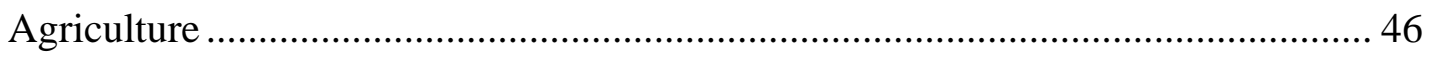

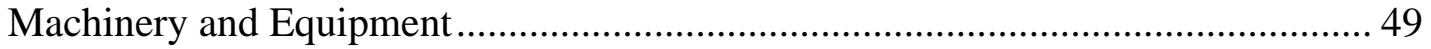

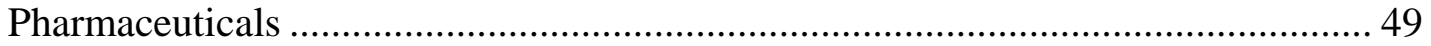

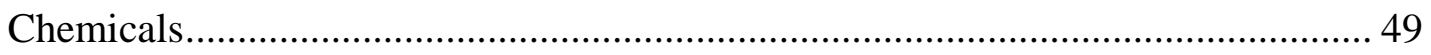

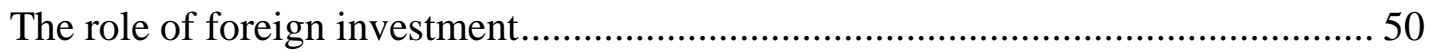

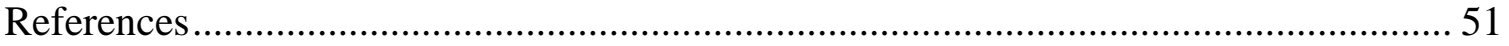




\section{Section 1: Does South Africa face an Export Predicament?}

\section{Export Performance, 1960 to 2004}

South Africa's output growth since 1960 has been rather disappointing, with GDP per capita in 2004 only $40 \%$ higher than it was in 1960 . This is compared to an increase over the equivalent period of $85 \%$ in Mexico, $130 \%$ in Egypt, and $168 \%$ in Malaysia ${ }^{1}$. But South Africa's export performance during this period has been even more dismal.

Although exports have grown in absolute terms over the past 40 years, exports per capita as of 2004 are barely higher than they were in 1960. Exports per capita in constant USD in 2004 were $\$ 918.58$, up from $\$ 663.91$ in 1960 , representing an annualized growth rate of only $0.64 \%$ p.a. (see Figure 1 ).

\section{Figure 1}

\section{GDP per capita (pink) and Exports Per capita (blue) in South Africa, 1960-2004}

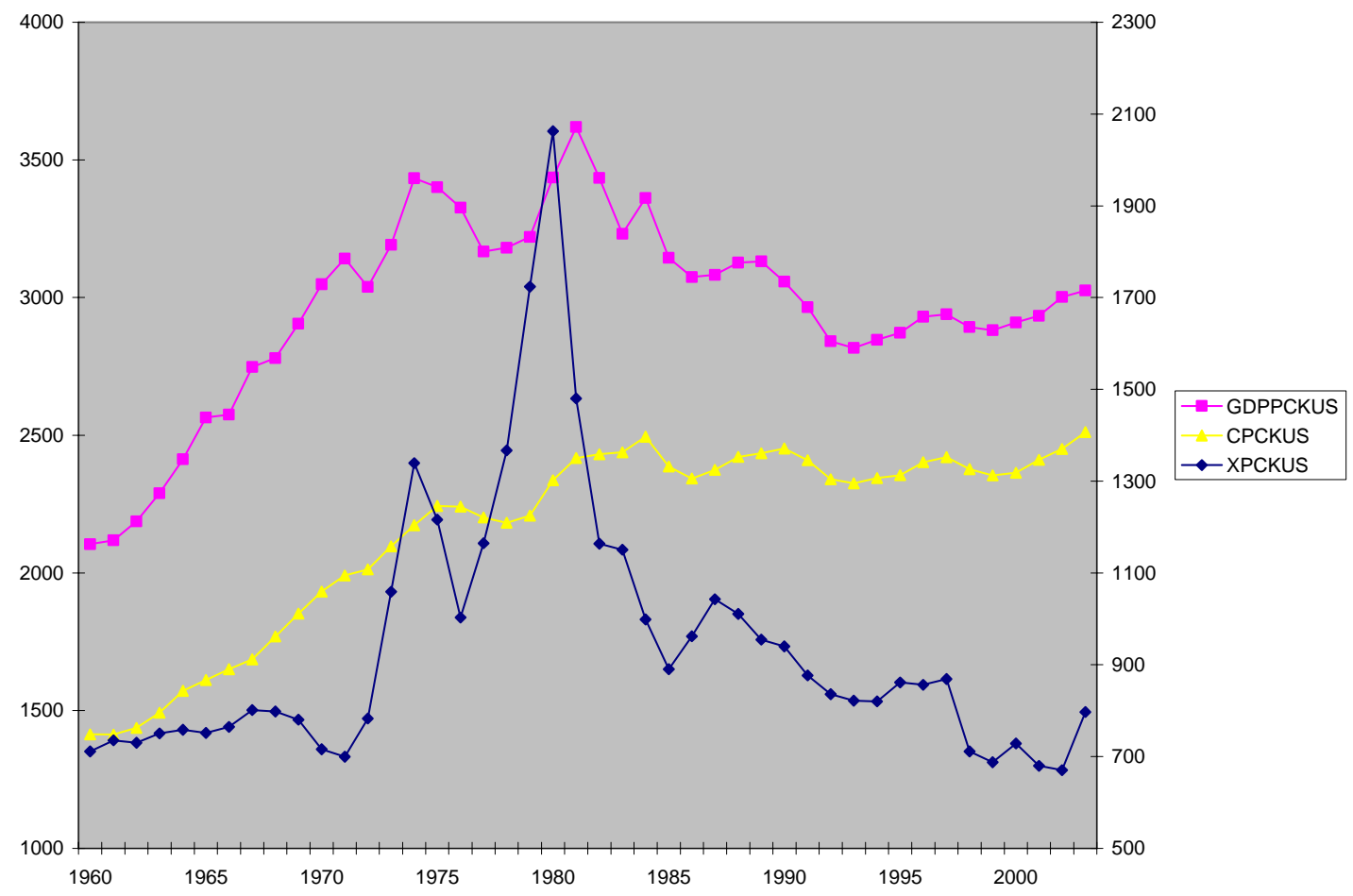

Source: World Bank World Development Indicators (2005)

This export performance is extremely poor when compared internationally. Considering all countries with a population over 4 million and GDP per capita of at least $25 \%$ of South Africa's (a relevant comparator group), South Africa is an outlier in terms of export performance, ranking $50^{\text {th }}$ out of 56 countries. Figure 2 shows the distribution of international growth rates in exports per capita.

\footnotetext{
${ }^{1}$ World Bank WDI
} 
Figure 2

Histogram of Growth in Exports Per Capita 1960-2004 ${ }^{2}$

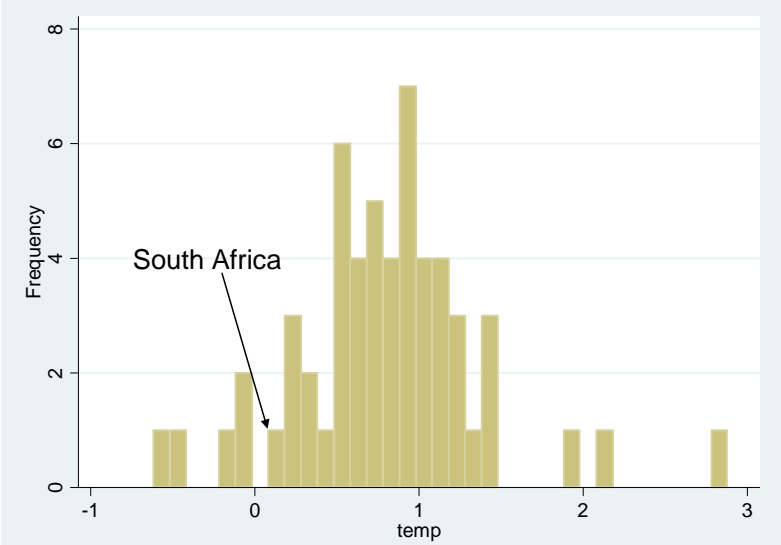

Source: Authors’ calculations using World Development Indicators (2005).

One may attribute this weak export performance to South Africa's status as a natural resource exporter, notwithstanding recent evidence that the 'natural resource curse' isn't much of a curse after all (Ferranti, Perry, Lederman \& Maloney 2002). Yet this poor export performance is low even among natural resource exporters. The Figure below shows exports per capita for South Africa and five other countries: Argentina, Australia, Canada, Malaysia, which each country’s exports per captia in 1960 indexed to 100. Each of these countries was a natural resource exporter as of 1960, and still vastly outperformed South Africa over the subsequent four decades.

\section{Figure 3}

Exports per capita among Natural Resource Exporters

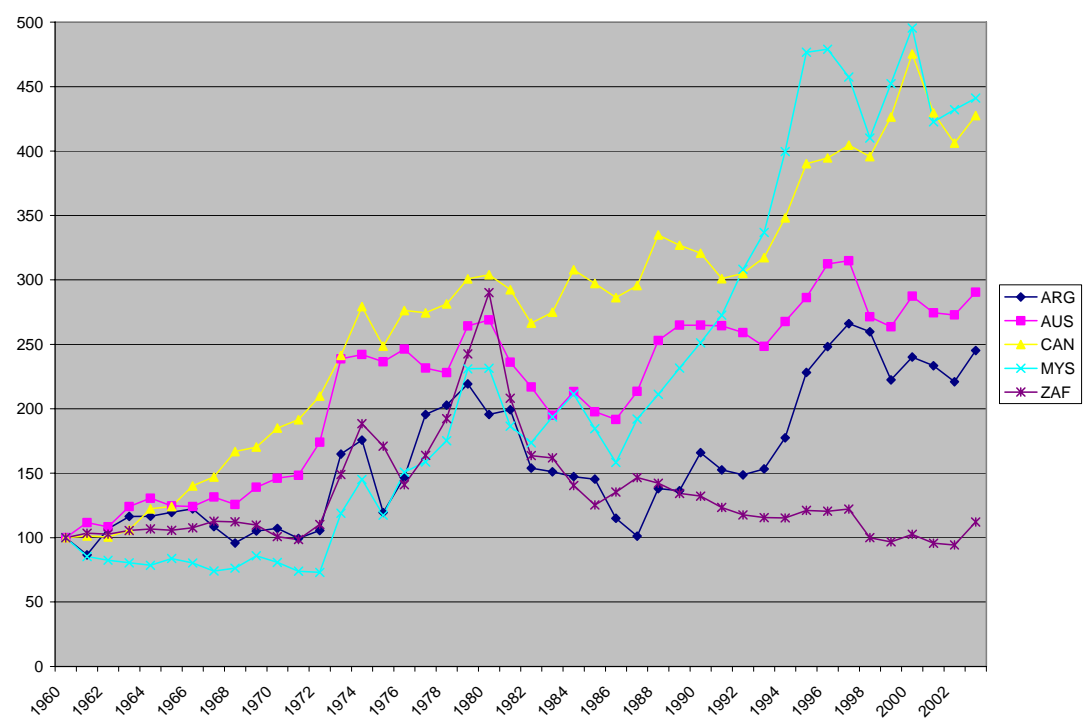

Source: Author's calculations using World Bank World Development Indicators

${ }^{2}$ Considering all countries with populations greater than 4 million and GDP per capita at least $25 \%$ of that of South Africa as of 2004 
Perhaps this poor performance is a legacy of apartheid-related sanctions, or exogenous changes in the prices of South Africa's particular exports. We can consider South Africa's exports in their best light by looking at export volumes during the period of time in which they underwent a sustained increase: the 1991-2004 period (see Figure 4).

\section{Figure 4}

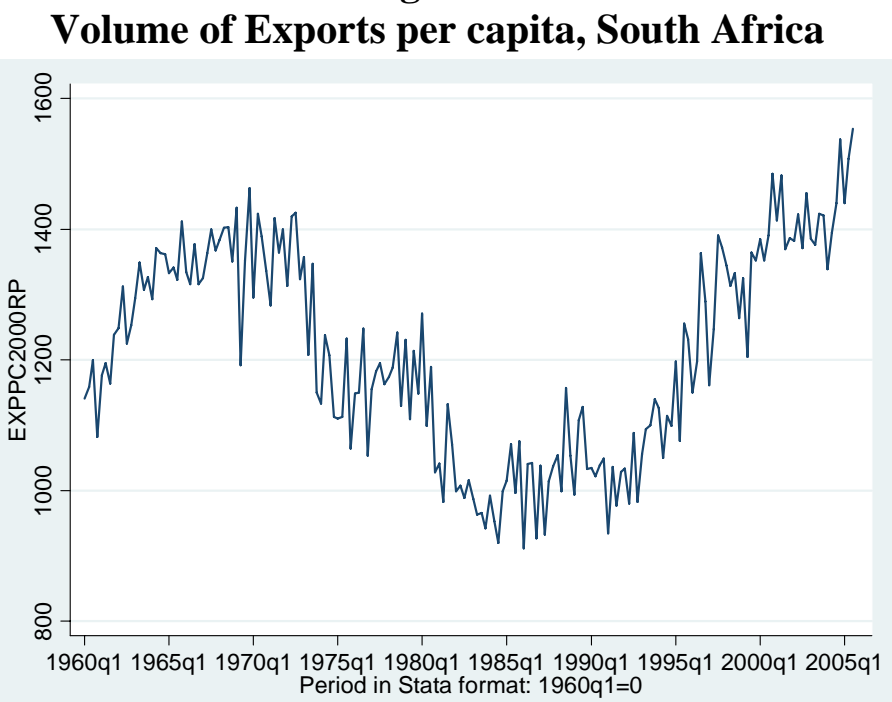

Source: IMF IFS

But even when we try to paint the rosiest picture of South Africa's export performance, the result is comparatively poor. Figure 5 shows that South Africa still remains among the poor performers internationally in terms of export growth.

Figure 5

Cross-Country Histogram of Growth in Export Volumes, 1991-2004

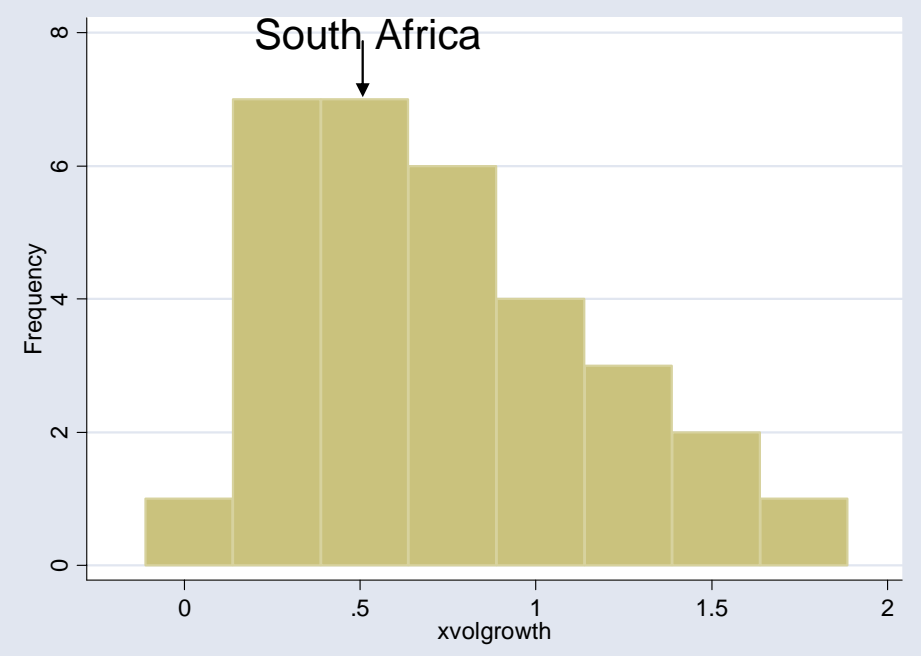

Source: Author’s calculations using IMF IFS 
A principal cause behind the poor export performance is the fact that mining faces a rather fixed endowment in a country where the population has been rising. For example, in 1960, South Africa was a country with a population of 17 million. Today, South Africa is a country of 47 million. Mining has not been able to keep up with population growth as shown in Figure 6.

\section{Figure 6}

\section{South Africa, Mining Per Capita}

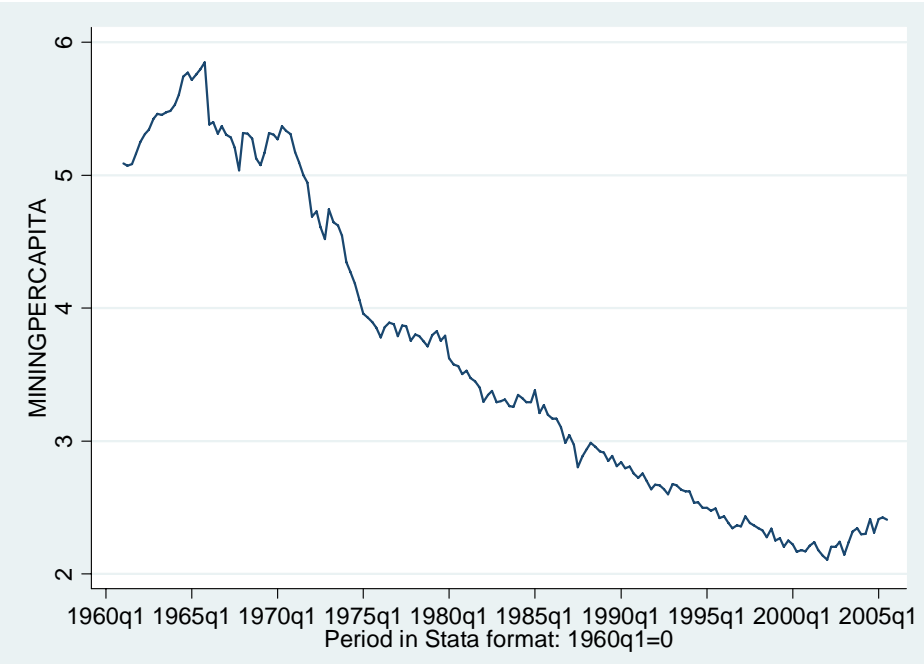

Source: IMF IFS

Has output in other activities grown enough to compensate for this decrease in per-capita mining output? Figure 7 shows that manufacturing per capita did expand in the 60s and early 70s, but since then has been quite stagnant.

Figure 7

South Africa, Manufacturing Output Per Capita

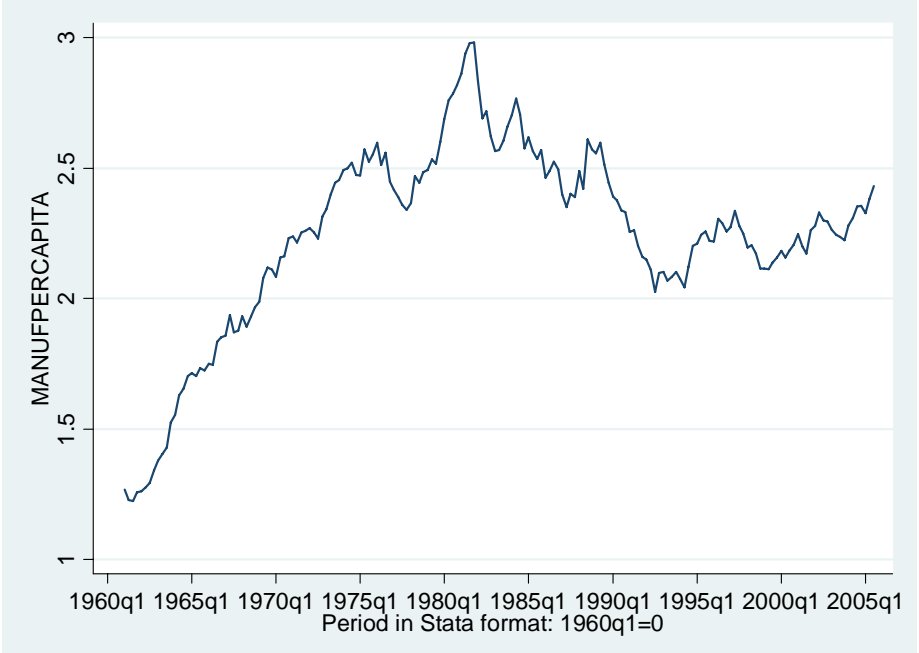

Source: IMF IFS 
Even today, South Africa's comparative advantage in exports is concentrated in mining and metals. As shown in Figure 8, the principal sectors showing large net exports are mining (gold (230), coal (210), other mining (220) and basic iron and steel (351)). Other net exporters are rather small (agriculture, beverages, tobacco, and refined products). Sectors such as automobiles, other machinery \& equipment, other transportation, food, and leather products are exported in large amounts, but are offset by even larger imports of those goods. It is only in mining, specifically gold, platinum, iron ore, and coal, that South Africa has large net exports.

\section{Figure 8}

\section{South Africa Export-output ratio vs. Import-domestic demand ratio, 2004 by SIC}

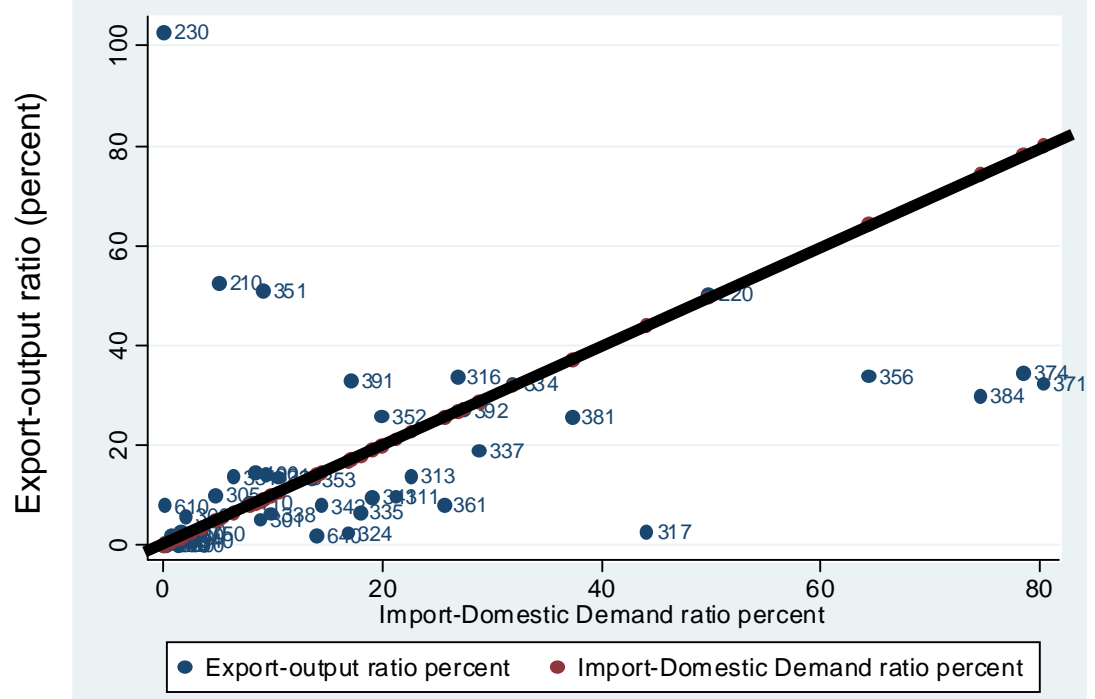

Source: Author's calculations using TIPS 


\section{The level of sophistication of exports}

It is not only in the amount of exports, but also in the composition of exports that South Africa is lagging. Recent work by Hausmann, Hwang and Rodrik (2006) finds that is not only how much, but also what you export that matters for growth. Using worldwide export data at multiple levels of disaggregation by product, the authors develop a measure of the revealed sophistication of each product, which they call PRODY. This is a measure of the GDP per capita of each country that exports the good, weighted by the relative share in the export basket:

$$
P R O D Y_{k}=\sum_{j} \frac{\left(x_{j k} / X_{j}\right)}{\sum_{j}\left(x_{j k} / X_{j}\right)} Y_{j}
$$

where $x_{j i}$ equals exports of good $k$ by country $j, X_{j}$ equals total exports by country $j$, and $Y_{j}$ equals GDP per capita of country $j$. This measure of sophistication for each product is then used to measure the sophistication of a country's entire export basket, which they call EXPY. EXPY is simply the PRODY of each good the country exports, weighted by that good's share in the country's export basket. It represents the income level associated with a country's export package.

$$
E X P Y_{i}=\sum_{l}\left(\frac{x_{i l}}{X_{i}}\right) P R O D Y_{l}
$$

Not surprisingly, the level of income associated with a country's export basket (EXPY) rises with actual income. That is, rich countries produce rich country goods.

\section{Figure 9}

\section{EXPY vs. GDP per captia, 2003}

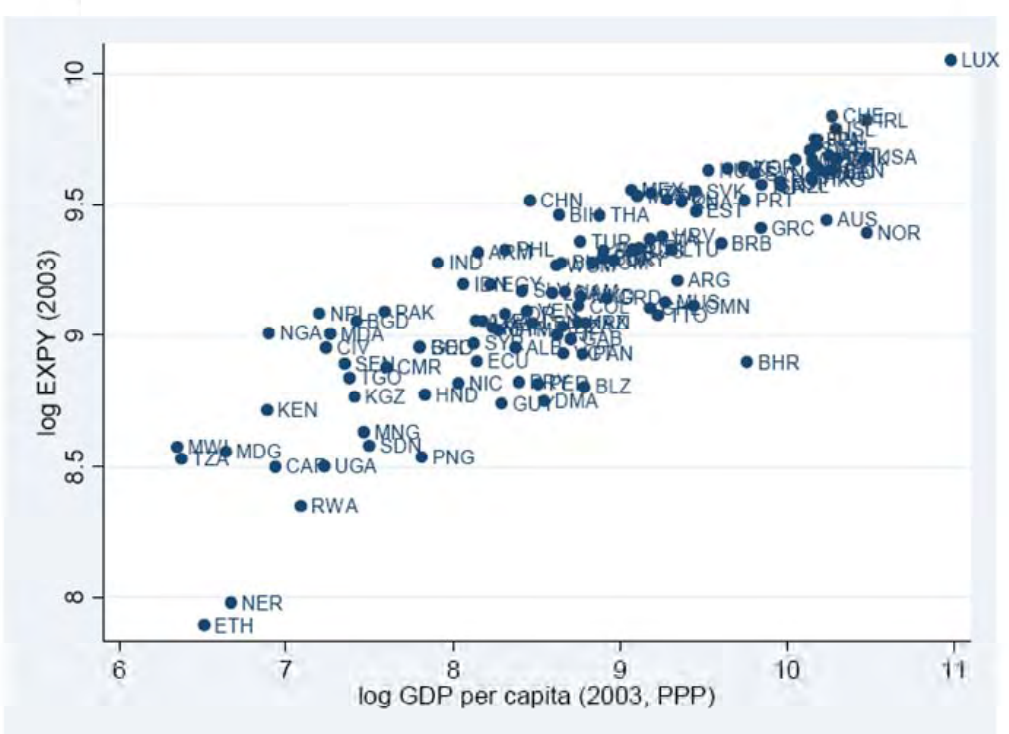

Source: Hausmann Hwang and Rodrik 2006 
However, the authors also find that after controlling for the level of income, a higher EXPY leads to subsequent growth in GDP per captia. This finding is robust to controlling for fixed effects, levels of human capital, and institutional quality. Countries that are able to successfully export products that are relatively sophisticated given their level of development experience faster GDP growth. In a way, countries 'become what they export'.

How does South Africa stack up in terms of the sophistication of its export package? As of 1975, the country had a relatively unsophisticated export package for its level of income.

\section{Figure 10}

\section{EXPY vs. GDP per capita, 1975 (South Africa Shown in Red)}

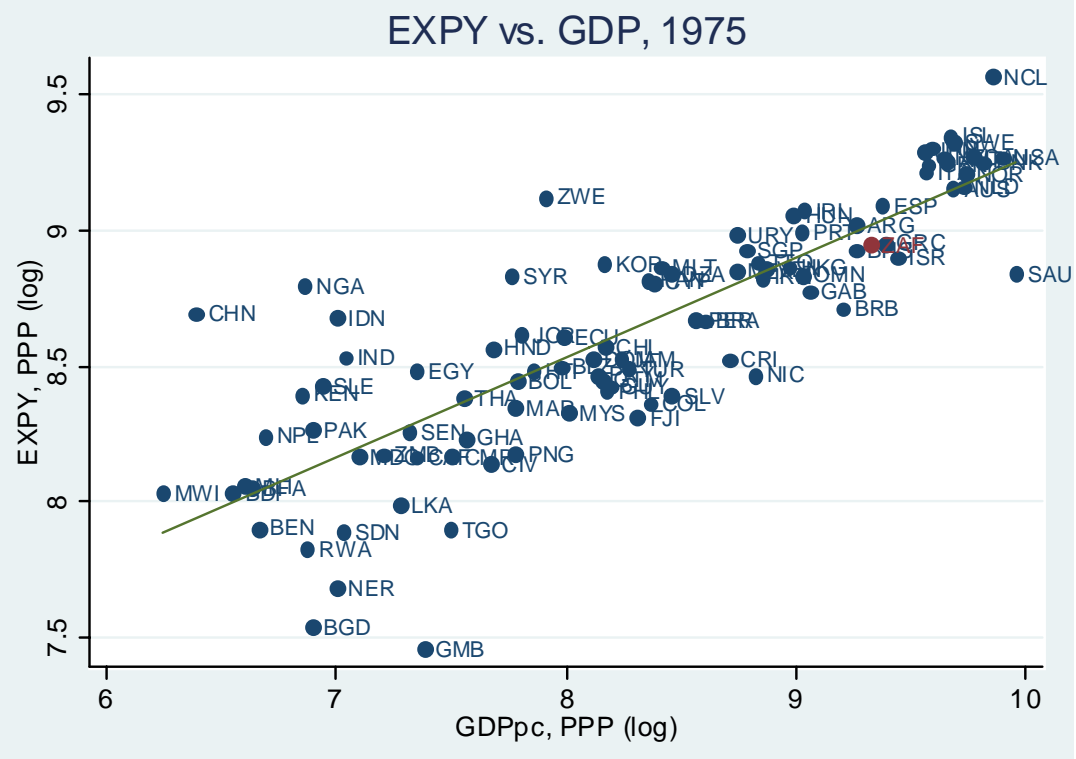

Source: Author’s Calculations using Feenstra et. al. 2005

Over time, the relative sophistication of South Africa's export package has improved slightly. Figure 11 shows that as of 2004, the country is no longer below the regression line. However, it is important to note that this is as much due to a relative decrease in GDP per capita (movement leftwards) as it is due to an increase in the sophistication of the export package (movement upwards). 


\section{Figure 11}

\section{EXPY vs. GDP per capita, 1975 (South Africa Shown in Red)}

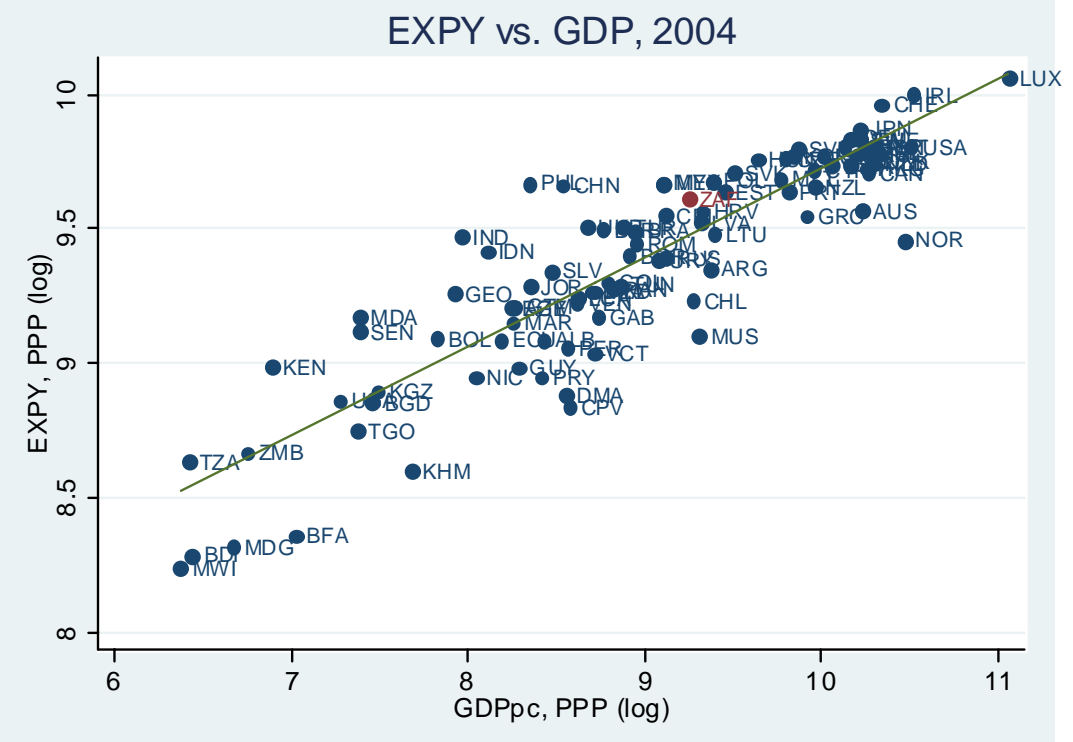

\section{Source: Author's Calculations using UN COMTRADE HS4}

In this light, the stagnation in South Africa's GDP per capita over the last 30 years is perhaps not as surprising. The sophistication of the export package has been week and hence has represented a limitation on subsequent growth of GDP and exports. As Figure 12 shows, for much of South Africa's history, GDP has been pulled down by the low level of sophistication of its export basket.

Figure 12

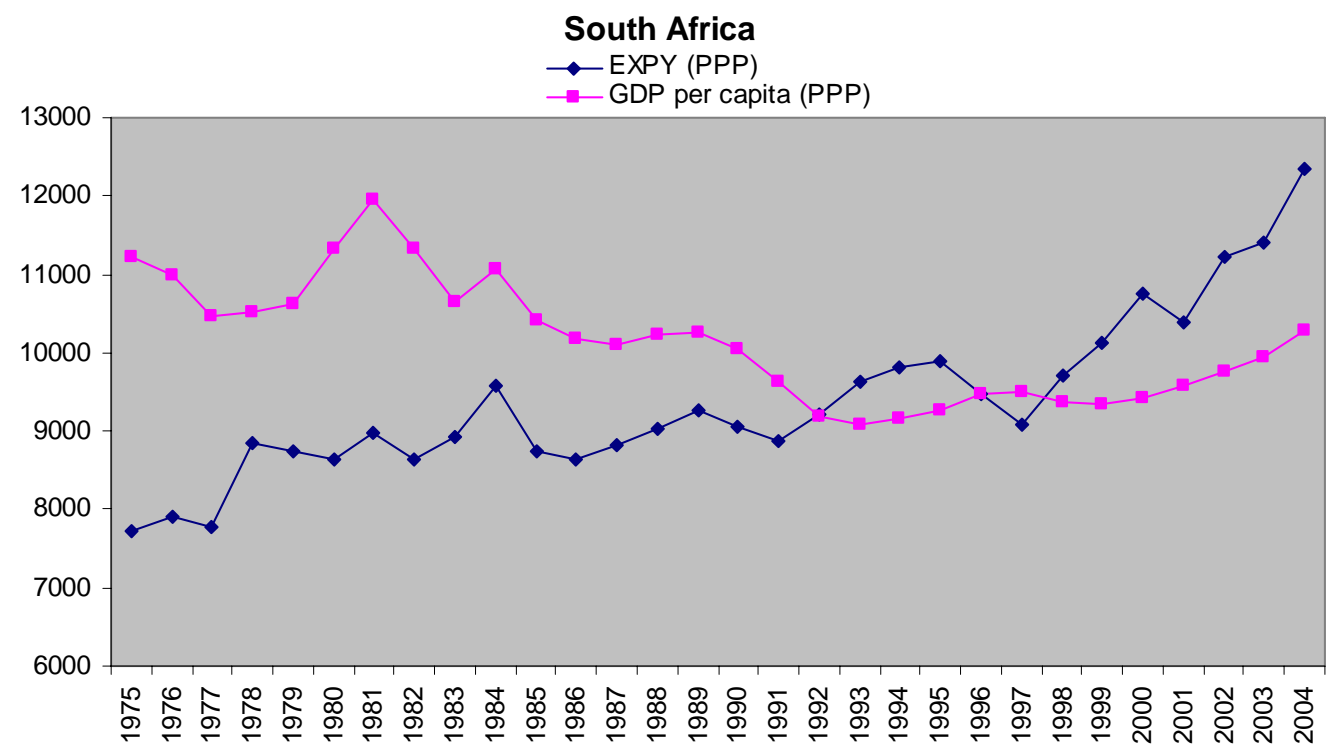

Source: GDP from World Bank WDI. EXPY from author's calculations using Feenstra et. al. (2005) for the 1975-2000 period, and UN COMTRADE for the 2000-2004 period, merged using relative changes from 2000 observation which is common to both series. 
This seems to have reversed itself in the 1990s, when South Africa experienced a marked increase in the sophistication of its export package, largely through increased exports of cars, motor vehicle parts and chassis, filtering and purifying machines for liquids and natural gasses, pharmaceuticals, and ferro-alloys. However, our measure of EXPY trends up with global growth. Therefore, it is important to compare South Africa's growth in EXPY with that of other countries. Figure 13 below plots EXPY from 1975 to 2004 for Chile, Mexico, Malaysia, and South Africa. Although South Africa started in 1975 with the highest EXPY in this group, it was overtaken in the 80s by both Mexico and Malaysia. Furthermore, the growth in EXPY after 1997, while a positive development, is not overly impressive in comparison to other countries.

\section{Figure 13}

\section{EXPY Over Time}

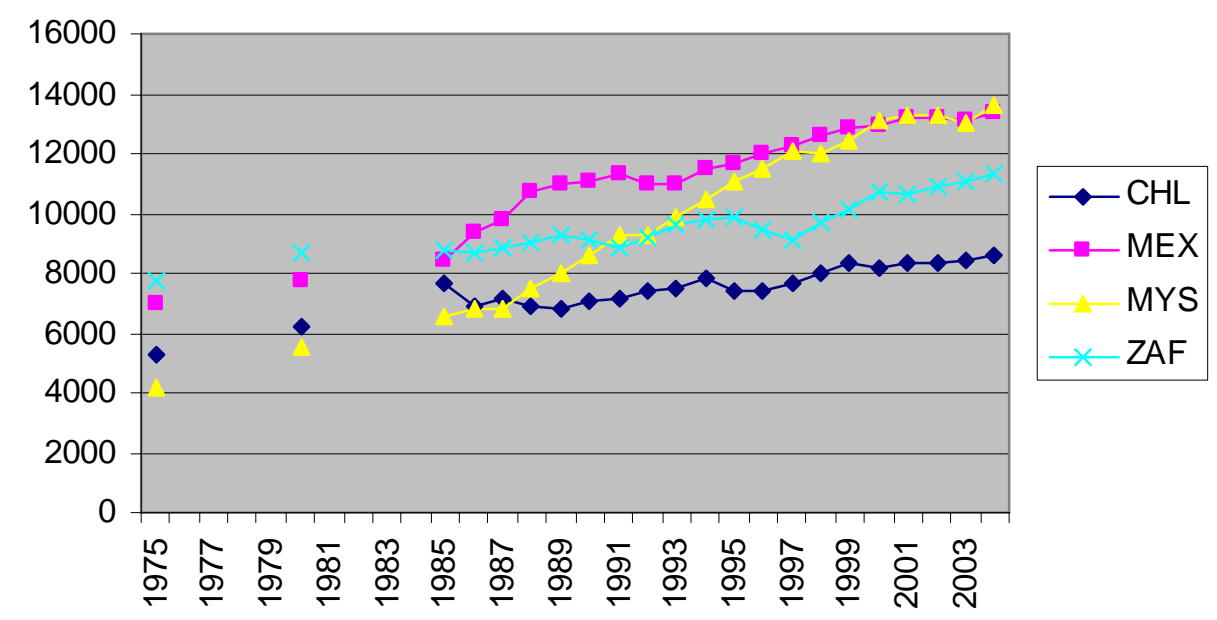

Source: Author's Calculations using Feenstra et. al. (2005) for the 1975-2000 period, and UN COMTRADE for the 2000-2004 period, merged using relative changes from 2000 observation which is common to both series.

So in terms of export volumes, value, and sophistication, South Africa has been a relatively poor performer. Although it had a high-EXPY export basket in 1975, this export package was concentrated in mining activities. 


\section{Section 2: Structural Transformation in South Africa}

In standard trade theory, structural transformation is a passive consequence of changing factor endowments. South Africa had a large endowment of mineral resources, and therefore its export basket was concentrated in such goods. As population increased, the mining endowment per capita fell and endowments of unskilled labor and capital rose. Theory would predict that this new endowment mix should automatically manifest itself in a different export mix. However, there are many reasons why structural transformation may be more complicated than this picture suggests. Several factors may create market failures such as industry-specific learning by doing (Arrow 1962, Bardhan 1970) or industry externalities (Jaffe 1986). There may also be technological spillovers between industries (Jaffe, Trajtemberg and Henderson 1993). Alternatively, the process of finding out which of the many potential products best express a country's changing comparative advantage may create information externalities (Hausmann and Rodrik 2003) as those that identify the goods provide valuable information to other potential entrepreneurs but are not compensated for their efforts.

Hausmann \& Klinger (2006) investigate the determinants of the evolution of the level of sophistication of a country's exports. We argue that producing new things is quite different from producing more of the same, as each product involves highly specific inputs such as knowledge, physical assets, intermediate inputs, labor training requirements, infrastructure needs, property rights, regulatory requirements or other public goods. Established industries somehow have sorted out the many potential failures involved in assuring the presence of all of these inputs, which are then available to subsequent entrants in the industry. But firms that venture into new products will find it much harder to secure the requisite inputs. For example, they will not find workers with experience in the product in question or suppliers who regularly furnish that industry. Specific infrastructure needs such as cold storage transportation systems may be nonexistent, regulatory services such as product approval and phyto-sanitary permits may be underprovided, research and development capabilities related to that industry may not be there, and so on. In short, structural transformation may be held back if the current product mix is very different from other products a country might produce.

We find evidence supporting the view that the assets and capabilities needed to produce one good are imperfect substitutes for those needed to produce another good, but this degree of asset specificity will vary. Correspondingly, the probability that a country will develop the capability to be good at producing one good is related to its installed capability in the production of other similar, or nearby goods for which the currently existing productive capabilities can be easily adapted.

Given this varying degree of asset specificity, the speed of structural transformation will depend on the density of the product space near the area where each country has developed its productive capabilities. Traditionally, this space is taken as homogenous so that nearby products always exist and are at similar distances. However, we find that in 
fact the product space is highly heterogeneous, with highly dense areas in some parts of the product space and highly sparse in others.

This is found by first developing a measure of similarity between products We measure the distance between each pair of products based on the probability that countries in the world export both. If two goods need the same capabilities, this should show up in a higher probability of a country having comparative advantage in both. Formally, the inverse measure of distance between goods $i$ and $j$ in year $t$, which we will call proximity, equals

$$
\varphi_{i, j, t}=\min \left\{P\left(x_{i, t} \mid x_{j, t}\right), P\left(x_{j, t} \mid x_{i, t}\right)\right\}
$$

where for any country $c$

$$
x_{i, c, t}=\left\{\begin{array}{ccc}
1 & \text { if } & R C A_{i, c, t}>1 \\
0 & \text { otherwise }
\end{array}\right.
$$

and where the conditional probability is calculated using all countries in year $t$. This is calculated using disaggregated export data across a large sample of countries from the World Trade Flows data from Feenstra et. al. (2005).

The heterogeneity of the product space can be shown econometrically, yet it is much more revealing to illustrate these pairwise distances graphically. Using the graphical tools of network analysis, we can construct an image of the product space. All of these graphics were produced with Albert-Lazlo Barabasi and Cesar Hidalgo for forthcoming work.

Considering the linkages as measured in the 1998-2000 period, we first create the maximum spanning tree by taking the one strongest connection for each product that allows it to be connected to the entire product space. This is shown below in Figure 14.

\section{Figure 14}

\section{Maximum Spanning Tree}

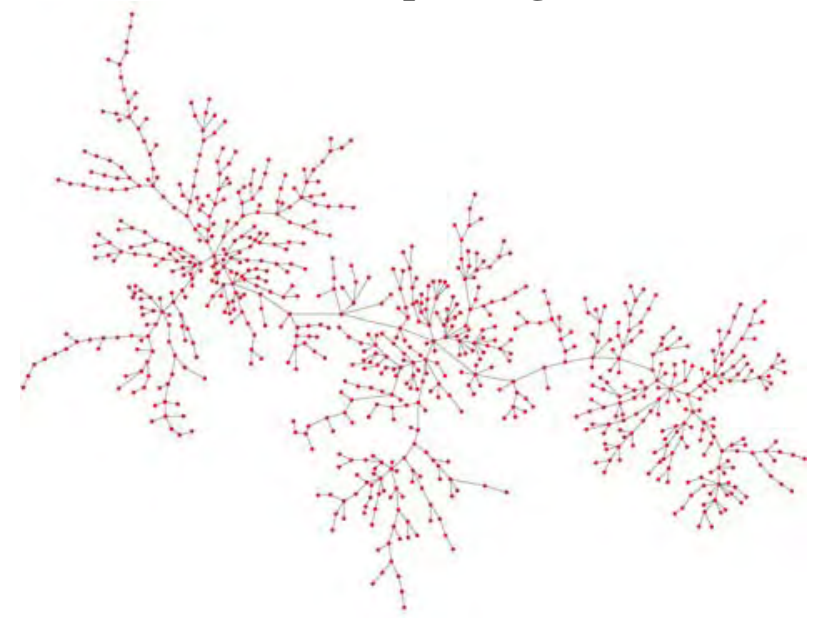

Source: Barabasi et. al., forthcoming 
The next step is to overlay this maximum spanning tree with the stronger links, and colorcode the linkages between products depending on their proximity. In Figure 15 below, we show the visual representation of the product space. Each node is a product, its size determined by its share of world trade. In these graphs, physical distances between products are meaningless: proximity is shown by color-coding the linkages between pairs of products. A blue link indicates a proximity of under .4, a beige link a proximity between .4 and .55 , a blue link a proximity between .55 and .65, and a red link a proximity greater than .65 . Links below 0.55 are only shown if they make up the maximum spanning tree, and the products are color-coded based on their Leamer (1984) commodity group.

\section{Figure 15}

\section{A Visual Representation of the Product Space}

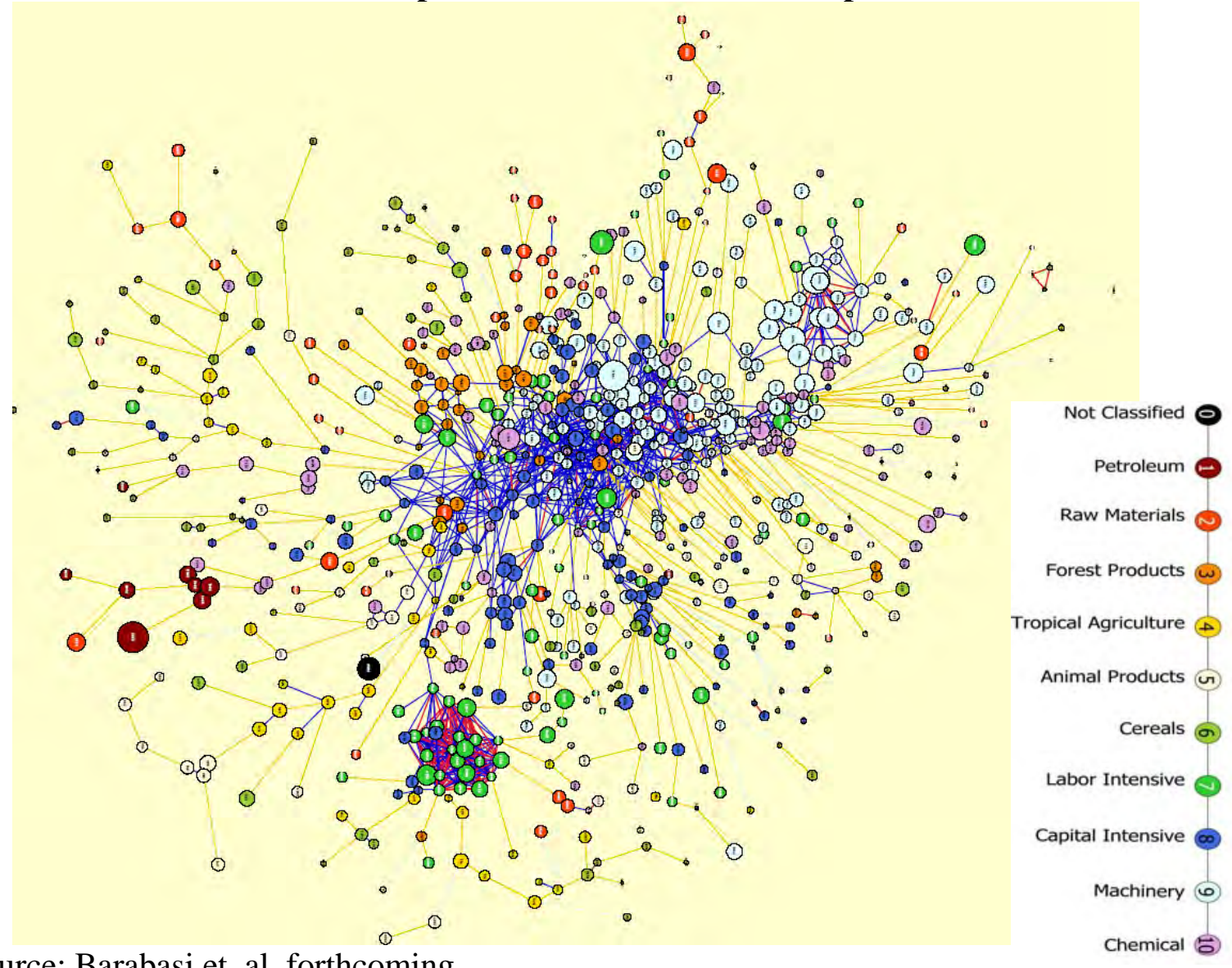

Source: Barabasi et. al. forthcoming

We can immediately see from Figure 15 that the product space is highly heterogeneous. There are peripheral products that are only weakly connected to other products. There are some groupings among these peripheral products, such as petroleum products (the large red nodes on the left side of the network), seafood products (below petroleum products), garments (the very dense cluster at the bottom of the network), and raw materials (the upper left to upper periphery). Furthermore, there is a core of closely connected products in the center of the network, mainly of machinery and other capital intensive goods. 
This heterogeneous structure of the product space has important implications for structural transformation. If a country is producing goods in a dense part of the product space, then the process of structural transformation is much easier because the set of acquired capabilities can be easily re-deployed to other nearby products. However, if a country is specialized in peripheral products, then this redeployment is more challenging as there is not a set of products requiring similar capabilities. The process of structural transformation can be impeded due to the nature of the products that the country is specialized in.

This may explain South Africa's export predicament. Figure 16 shows which products in the product space South Africa has achieved comparative advantage in, at 5-year increments.

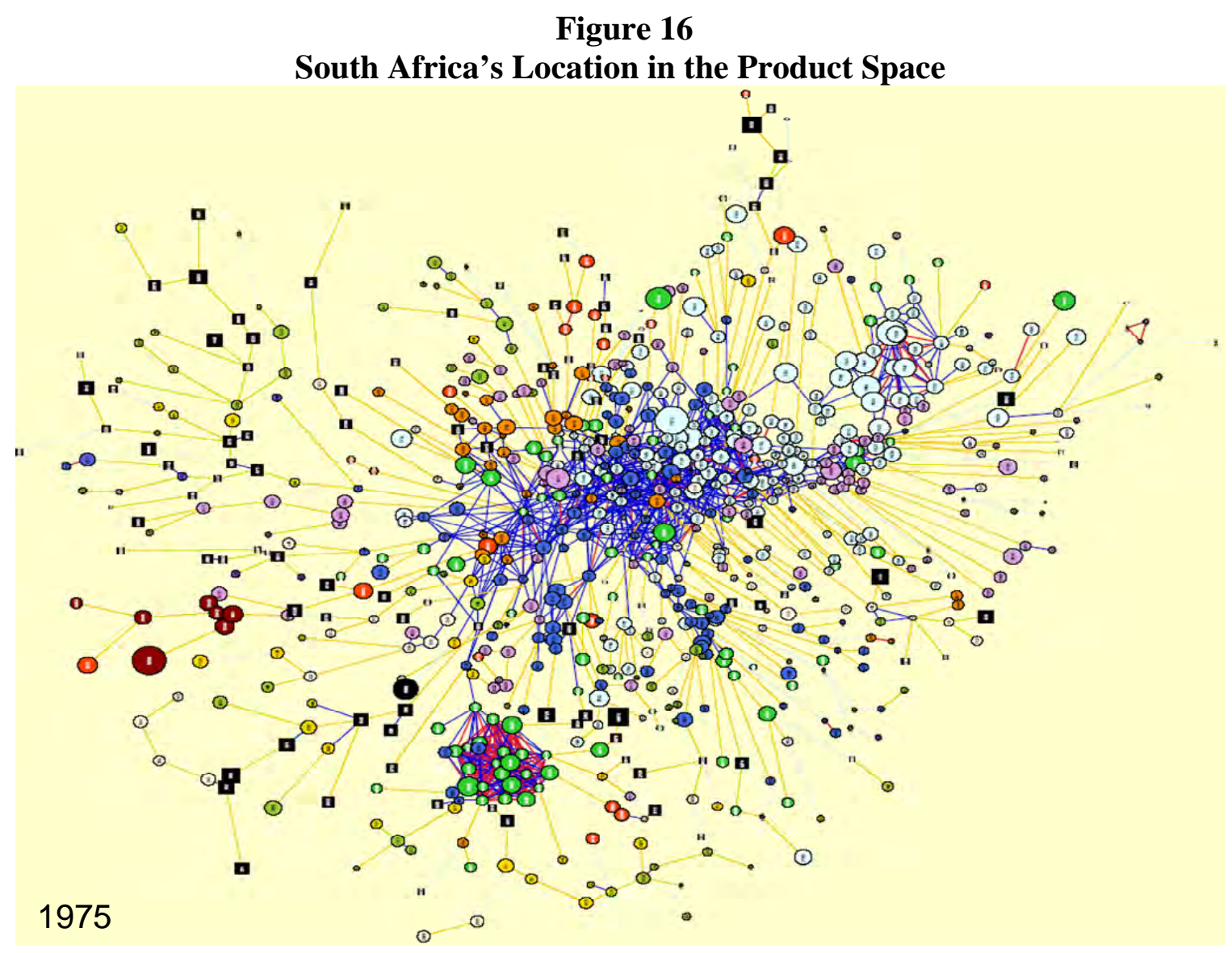




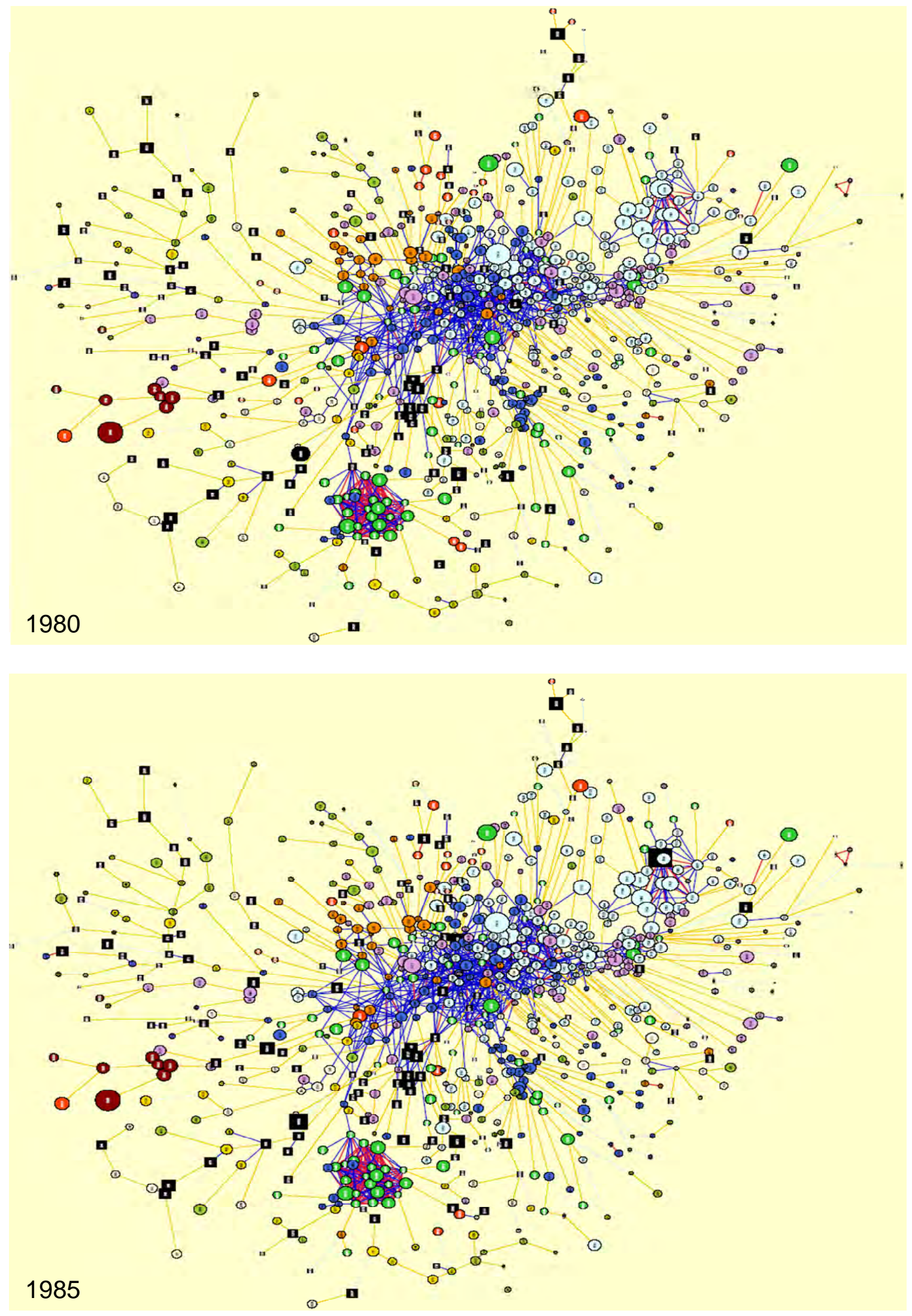




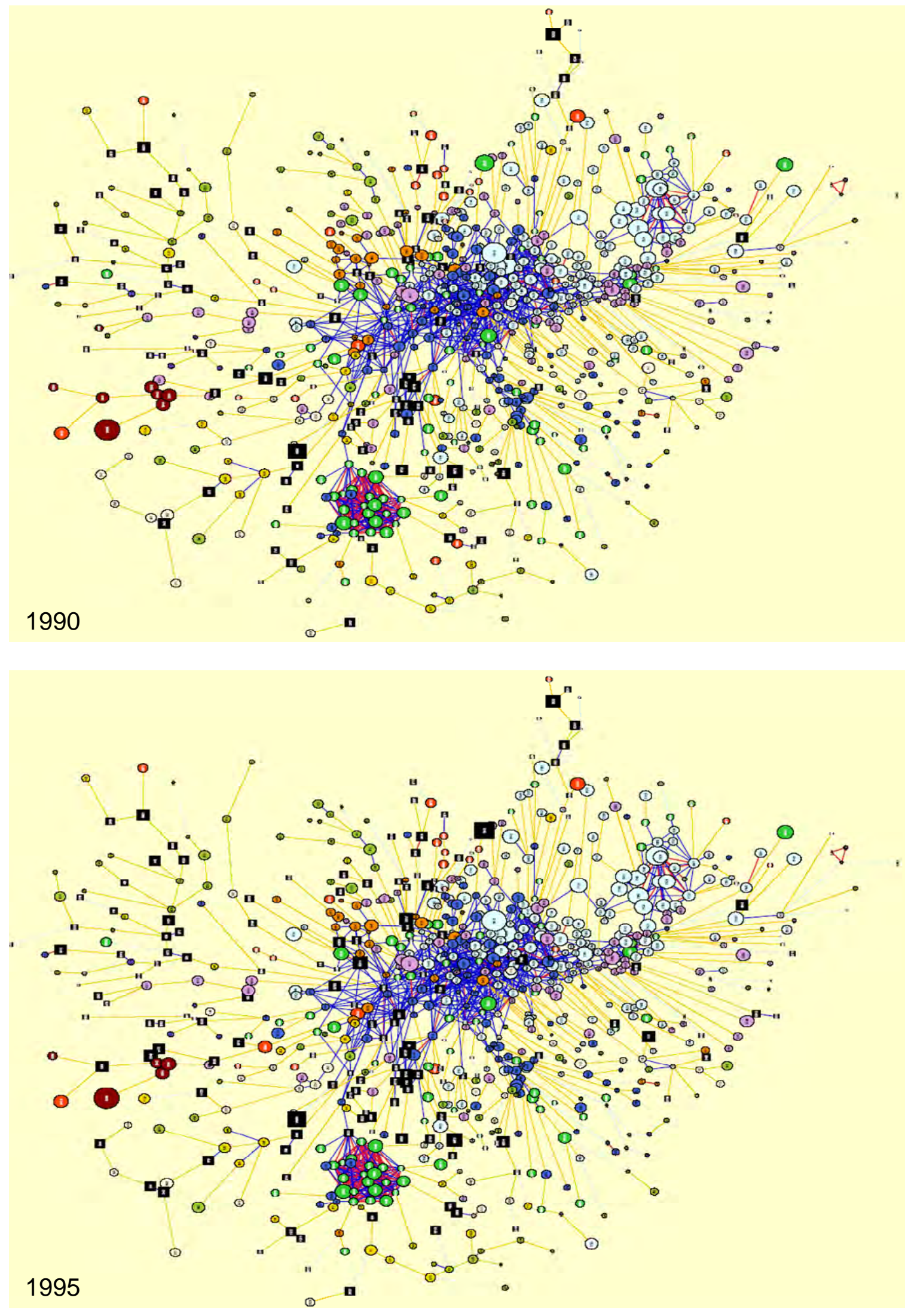




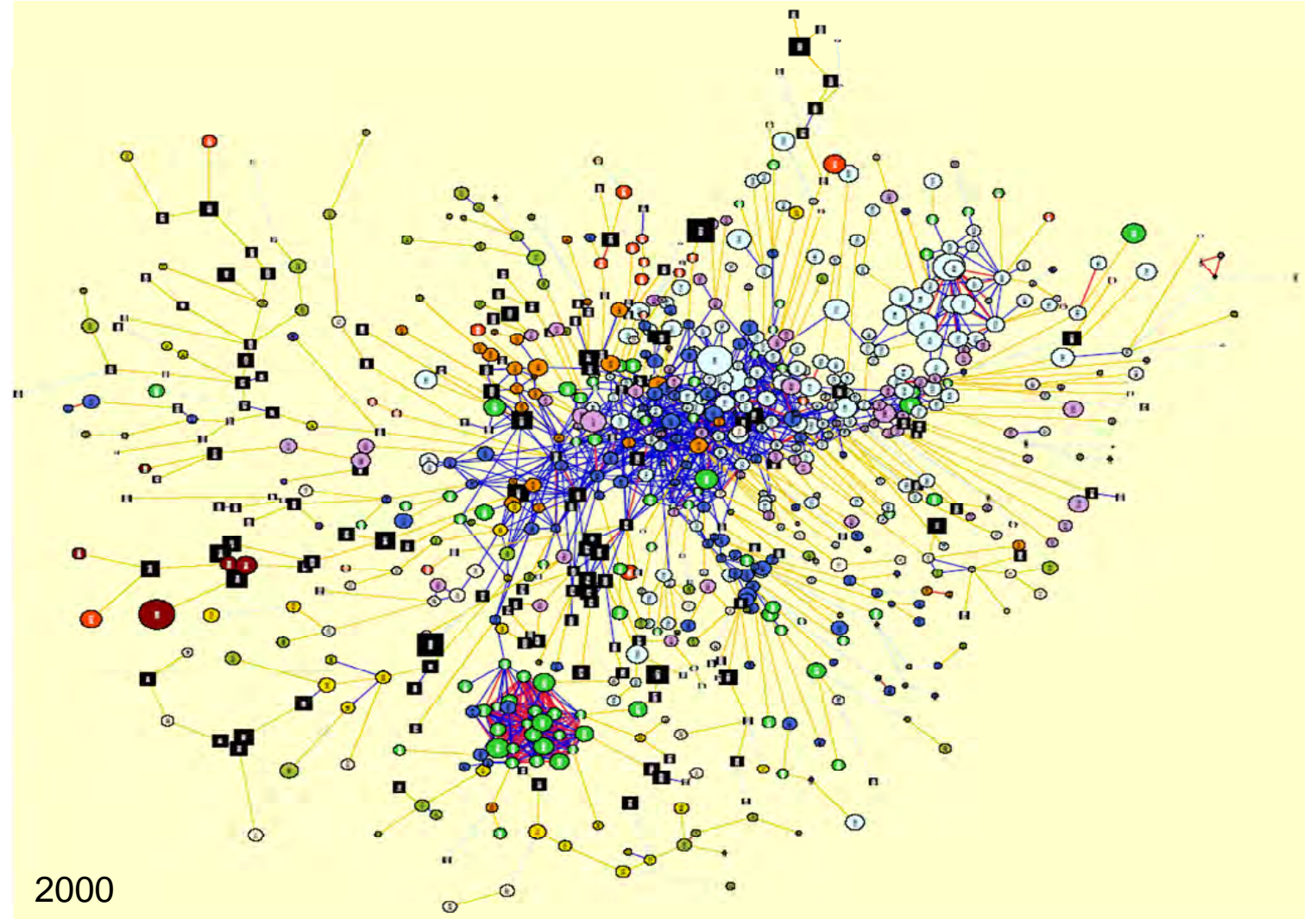

Source: Author's Calculations

These figures show that South Africa's production is largely located on the periphery of the product space. This is particularly true of earlier years, and there has been some recent movement to more central goods such as filtering \& purifying machines for liquids and natural gasses (and parts thereof), furniture, and paper products. Yet on the whole, these figures show peripheral production with little structural transformation to new products in South Africa. Compare this to the equivalent figures for Malaysia. Although that country has not moved heavily into the industrial core, there has been significant structural transformation, represented by rapid movement of production from peripheral goods to the cluster of electronics related goods in the upper-right portion of the space. 
Figure 17: Malaysia's Location in the Product Space

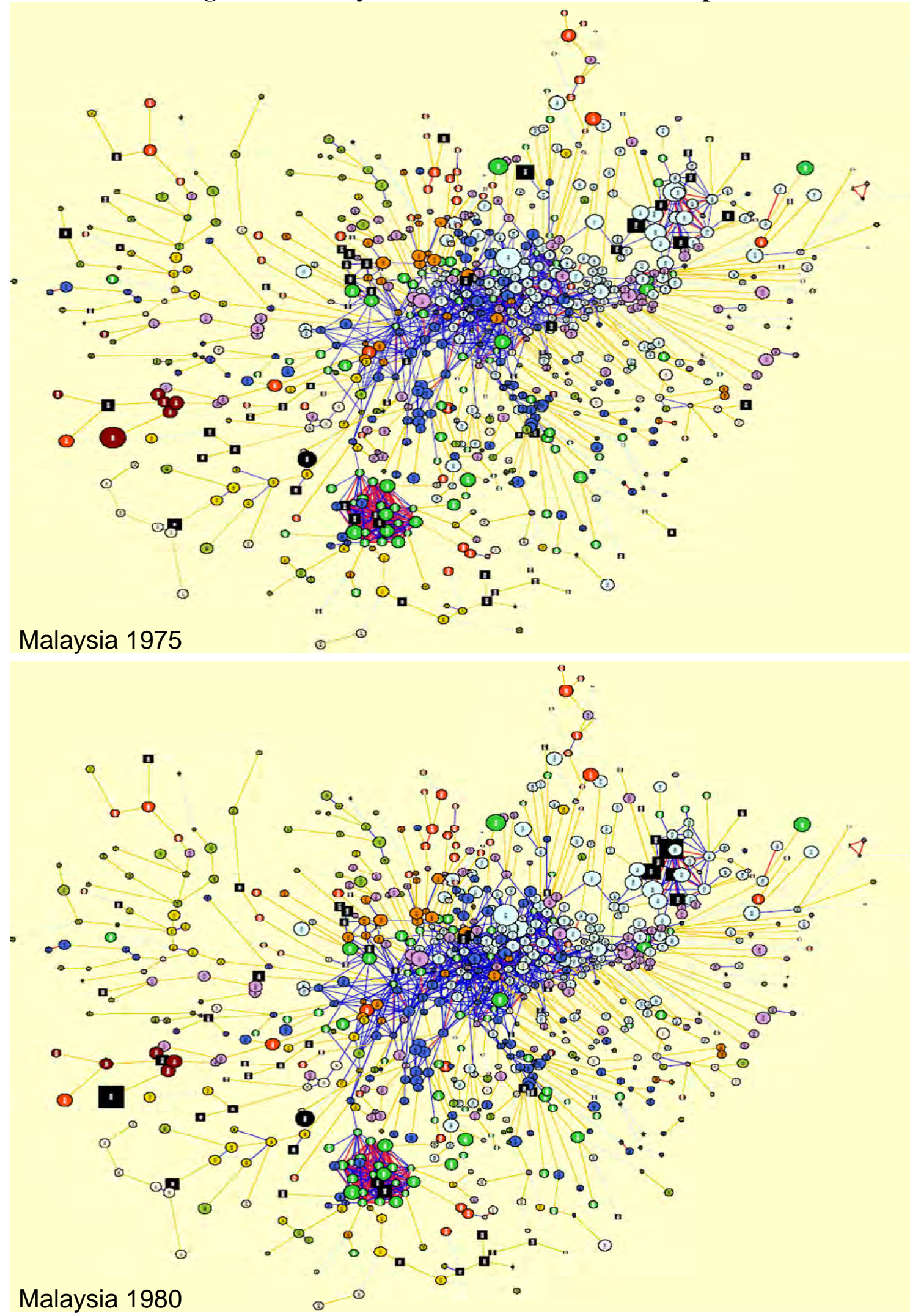




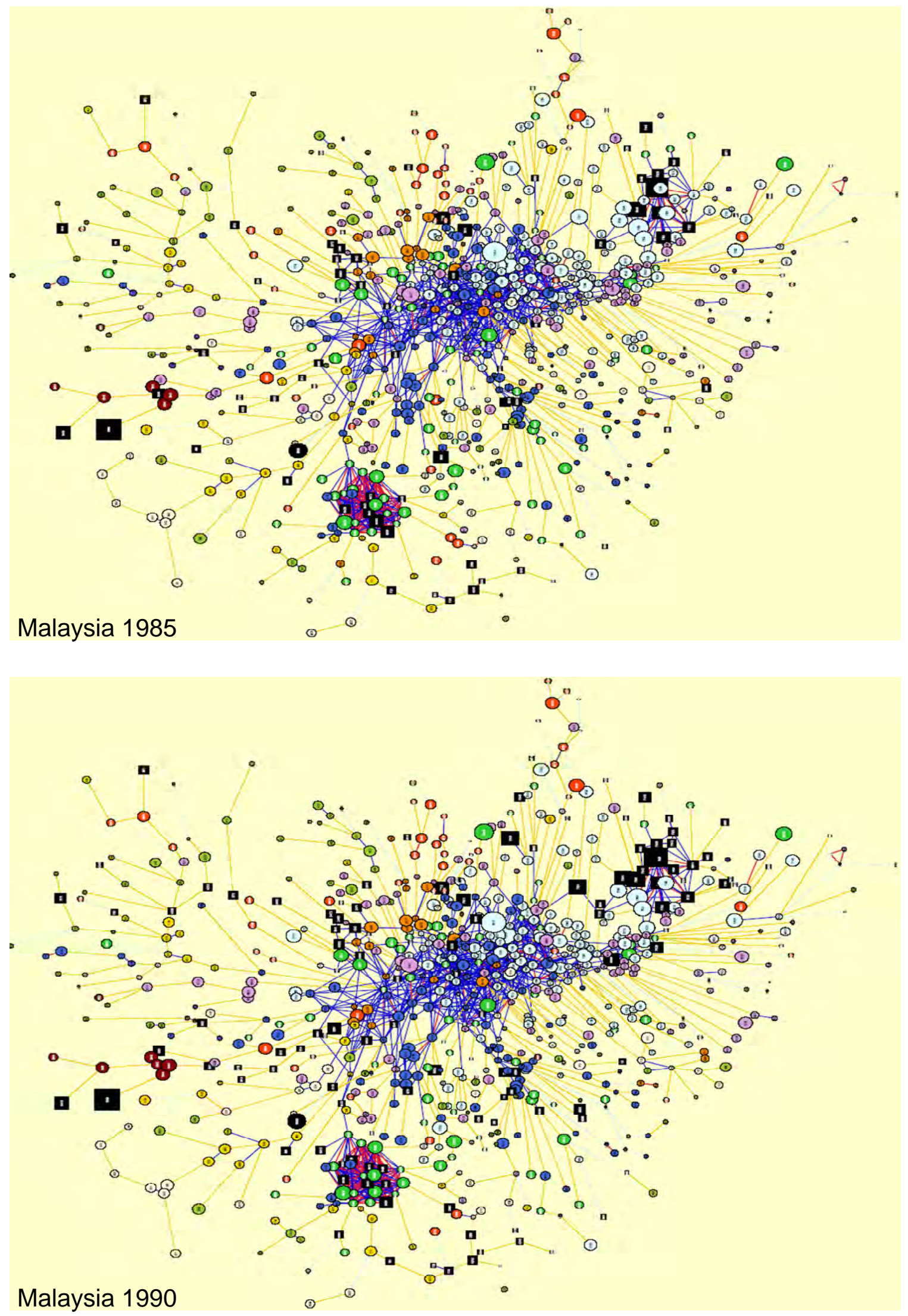




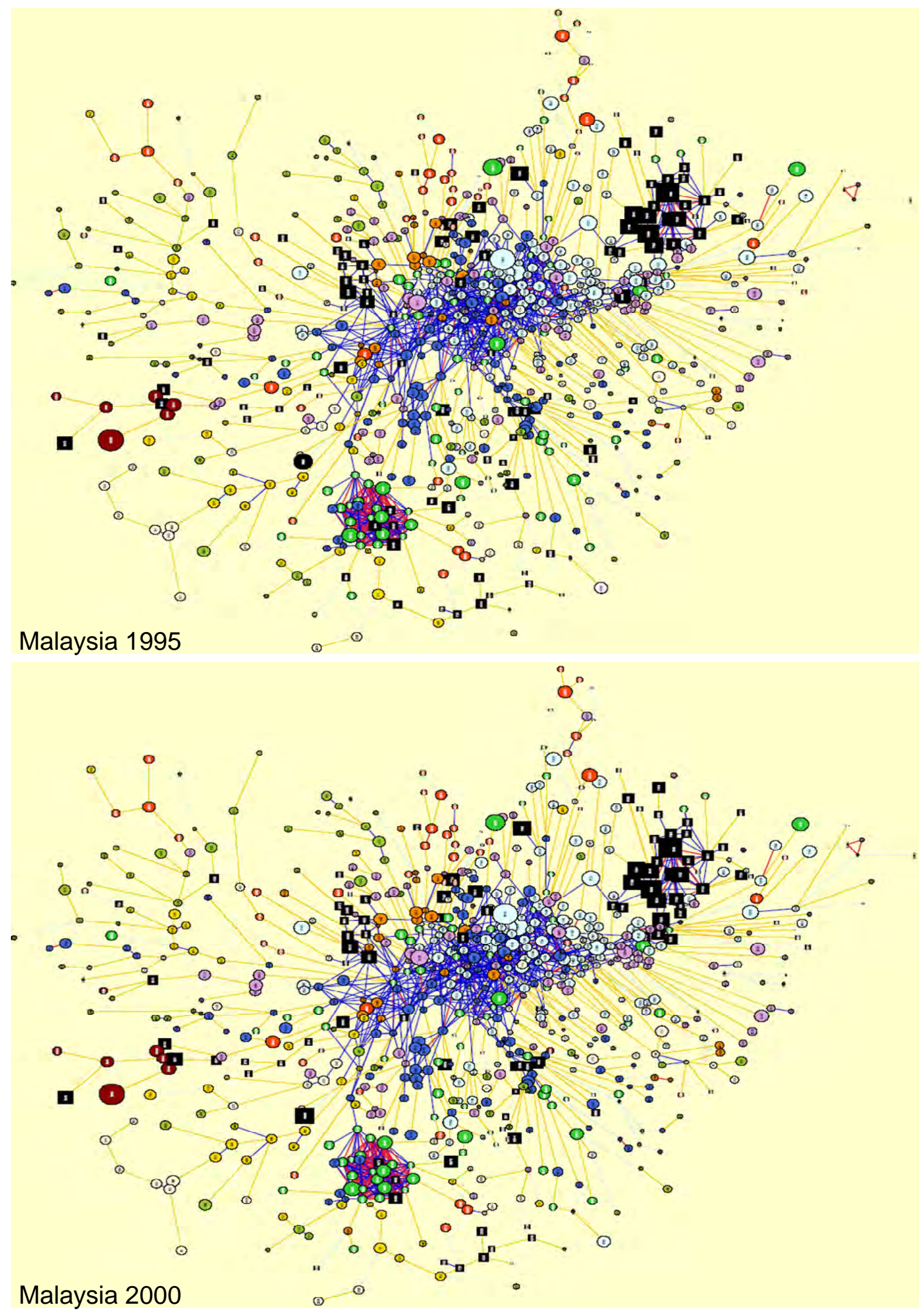

Source: Author's Calculations 
We can also use these pairwise proximities to measure the degree to which a country's current export basket is connected with new productive possibilities. This measure, called 'open forest', is calculated as follows:

$$
\text { open_forest }_{c, t}=\sum_{i} \sum_{j}\left[\frac{\varphi_{i, j, t}}{\sum_{i} \varphi_{i, j, t}}\left(1-x_{c, j, t}\right) x_{c, i, t} \text { PRODY }_{j, t}\right]
$$

Hausmann \& Klinger (2006) show that open forest is highly significant in determining the future growth of EXPY. We can use this metric to go behind South Africa's record of structural transformation over the past 4 decades. Figure 18 shows the evolution of export sophistication (EXPY) and open forest in South Africa.

Figure 18

\section{EXPY and Open Forest, South Africa}

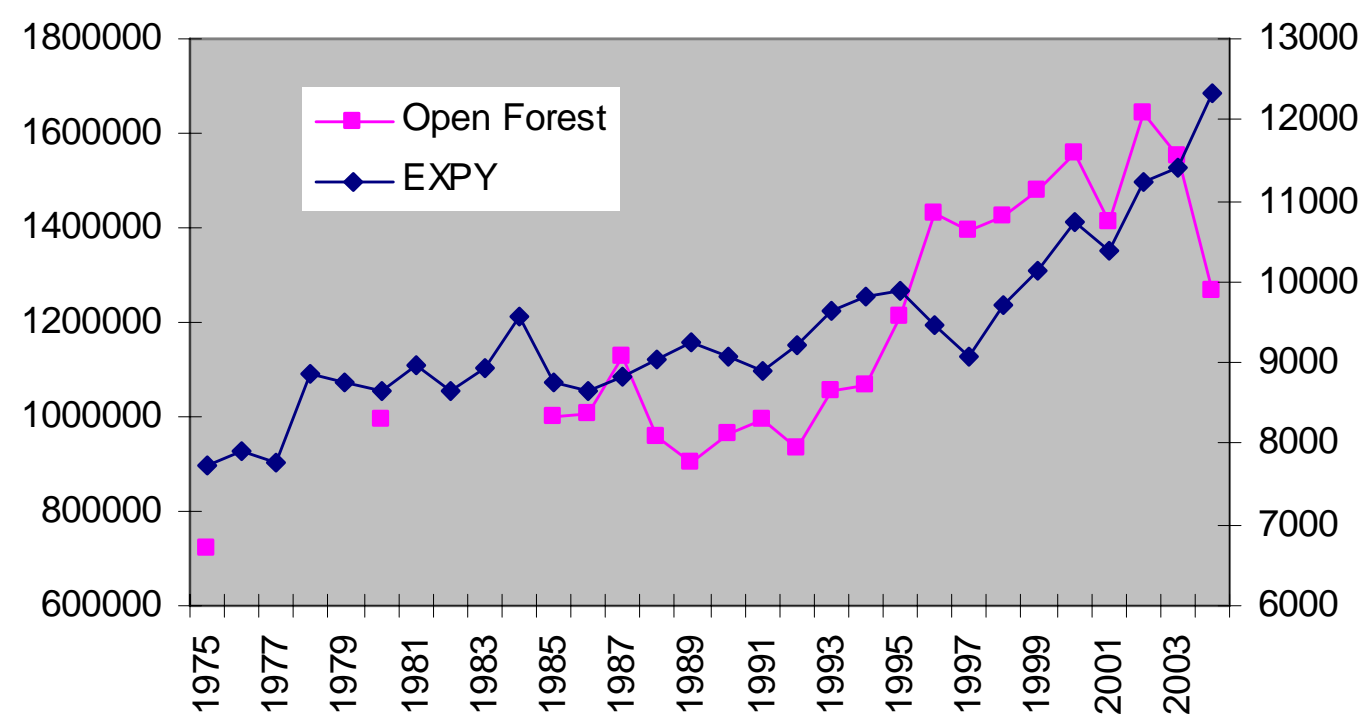

Source: Author's Calculations using Feenstra et. al. (2005) for the 1975-2000 period, and UN COMTRADE for the 2000-2004 period, merged using relative changes from 2000 observation which is common to both series.

In this light, the relatively low and stagnant export sophistication observed in South Africa during the 70s, 80s and early 90s in terms of structural transformation is not surprising. During these years, production remained on the periphery of the product space, and it was not until the early 1990s that there was some reorientation of the export basket that created new opportunities for structural transformation. The products that entered the export basket with revealed comparative advantage in the 1994-1996 period were various iron \& steel products, textile related products, non-metalic mineral manufactures, specialized machinery, organic chemicals, articles of pulp \& paper, vegetables \& fruits, petroleum products, metalliferous ores and metal scrap, oils \& light perfume materials, and leather manufactures. As figure 18 shows, this jump in open 
forest (which notably occurred during trade liberalization) was followed by the moderate improvement in export sophistication that continues today. But since 2001 the process has stopped. A stagnant or declining open-forest does not bode well for future increases in EXPY

How does South Africa's open forest stack up internationally? Figure 19 shows the evolution of open forest with the same three comparator countries. The improvement in open forest during the 1990s was significant, but its reversal has again placed South Africa's options for future structural transformation below those of Mexico and Malaysia, even though they are both also traditionally natural resource exporters.

Figure 19

\section{Evolution of Open Forest, Comparative}

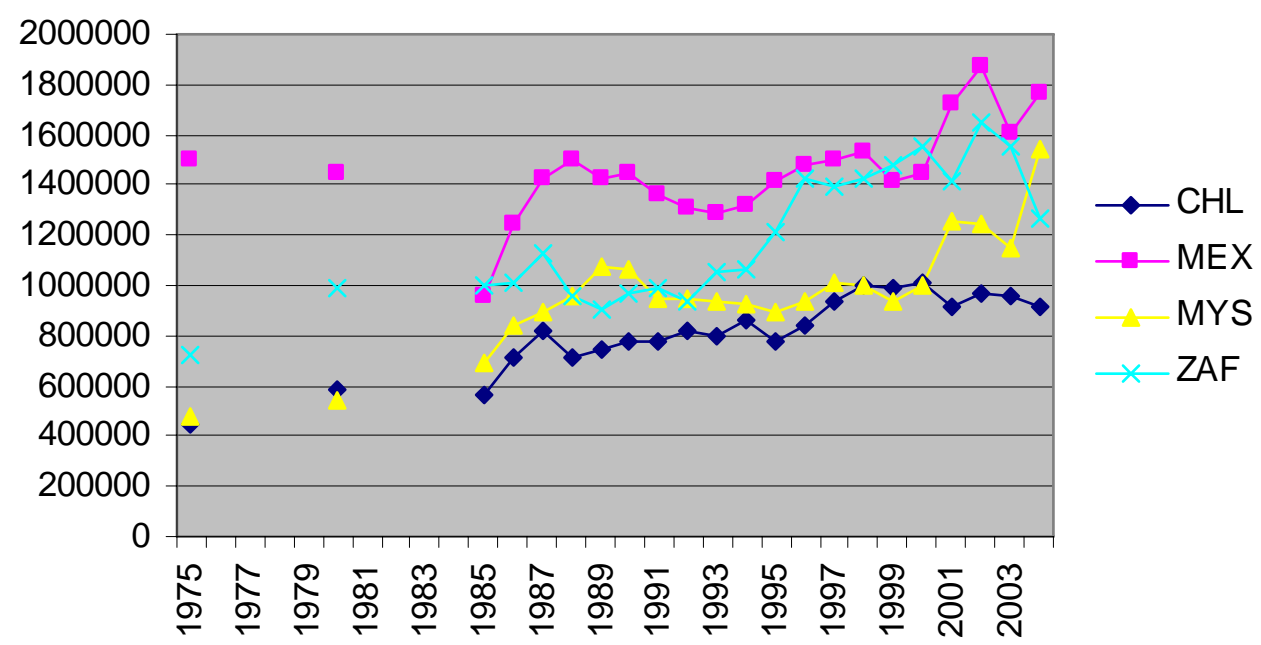

Source: Author's Calculations using Feenstra et. al. (2005) for the 1975-2000 period, and UN COMTRADE for the 2000-2004 period, merged using relative changes from 2000 observation which is common to both series.

Does poor positioning in the product space explain its slow structural transformation, or is there some other explanation unique to South Africa? One way to evaluate this proposition is to consider the estimated coefficients on the country dummy variables from the Hausmann \& Klinger (2006) regressions. Specifically, using a probit regression on all observations of non-exported goods from every country between 1985 and 2000 and estimating the full model (including factor endowments through RCA in the Leamer commodity cluster), the estimated coefficient on the country dummies captures the country characteristics that affect the probability of moving to new exports controlling for level of development, sophistication of the export package, and open forest. As table 1 shows, this estimated coefficient is statistically significant in some cases, suggesting either unexpectedly rapid structural transformation if positive, and unexpectedly slow structural transformation if negative. So while some factors other than location in the product space are particularly important in the cases of Spain, Romania, El Salvador, and Zimbabwe, in the case of South Africa there is no statistically significant tendency 
towards rapid or slow structural transformation controlling for open forest. That is, in the case of South Africa, much of its structural transformation predicament boils down to its placement in the product space. The tools to overcome this predicament likely lie in the area of trade policy (see Edwards and Lawrence) and industrial strategy, which we take up in the next section, followed by an evaluation of the DTI's current strategy in terms of sectoral focus.

Table 1

Estimated Coefficients on Country Dummies

\begin{tabular}{|l|c|}
\hline El Salvador & $\begin{array}{c}-0.010 \\
(3.91)^{* *}\end{array}$ \\
\hline Romania & 0.016 \\
& $(3.08)^{* *}$ \\
\hline Spain & 0.032 \\
& $(6.83)^{* *}$ \\
\hline South Africa & 0.003 \\
& $(0.44)$ \\
\hline Zimbabwe & -0.003 \\
& $(5.04)^{* *}$ \\
\hline
\end{tabular}

A positive value indicates movements to new products occurred with greater frequency than predicted by the Hausmann \& Klinger (2006) model.

T-statistics in parenthesis. **: significant at 1\% level. Source: Author's calculations. 


\section{Section 3: The Tradeoffs in Industrial Strategy}

When considering the products that South Africa could move to, we have identified a particularly important dimension: contribution to open forest, or what we will call strategic value. As can be clearly seen in Figure 15 above, not all products were created equal in terms of their strategic value. Some products are in a dense part of the product space, meaning that they use capabilities that are easily deployed to a wide range of other goods, and therefore successfully producing them would create capabilities with significant value for future structural transformation. On the other hand, other products are located in the periphery, or in a part of the product space where South Africa has already achieved comparative advantage and acquired the requisite productive capabilities, and therefore successfully producing these goods would offer little in terms of future structural transformation, even if they are highly valuable in their own right (i.e. have a high PRODY).

In addition to measuring strategic value, we are also able to measure the distance of any good from the country's current export basket. Use the pairwise proximity measures for each element of the country's entire export basket, we can measure the 'density' of current production around any good. It is the sum of all paths leading to the product in which the country is present, scaled by the total number of paths leading to that product. Density varies from 0 to 1 , with higher values indicating that the country has achieved comparative advantage in many nearby products, and therefore should be more likely to export that good in the future.

$$
\text { density }_{i, c, t}=\left(\frac{\sum_{k} \varphi_{i, k, t} x_{c, k, t}}{\sum_{k} \varphi_{i, k, t}}\right)
$$

Hausmann \& Klinger (2006) show that this measure of density is indeed a highly significant in predicting how a country's productive structure will shift over time: countries are much more likely to move to products that have a higher density, or are closer to their current production.

This implies a tradeoff: countries are more likely to successfully move to goods that are close to what they currently produce, because such goods require similar capabilities. Yet, such goods may or may not have much strategic value. They may be in a sparse part of the product space or may be so close that they do not imply the development of new capabilities that can be redeployed in other directions. So moving closer is easier, but moving further may be more valuable in terms of future structural transformation.

This tradeoff can be readily observed in Figure 20. This shows for all the products that South African did not have comparative advantage in as of 2004, their distance ($1^{*} \log ($ density), meaning that smaller values indicate the product is closer to the current basket), and strategic value, measured by the log of the marginal contribution to open 
forest if South Africa were able to achieve comparative advantage in that good. The ideal location on this plane is the upper-left quadrant: goods that are close and have high strategic value. We see a tradeoff between these two goals in that most very nearby goods offer little strategic value, and most goods with high strategic value are further away. While it is not necessarily the case that the products most attractive to South Africa are those that are easiest to move to (leftwards) instead of those with higher strategic value (upwards), or vice-verse, it is clear that there is an efficient frontier in this tradeoff, indicated in the figure.

Figure 20

South Africa's Open Forest, 2004: Proximity versus Strategic Value

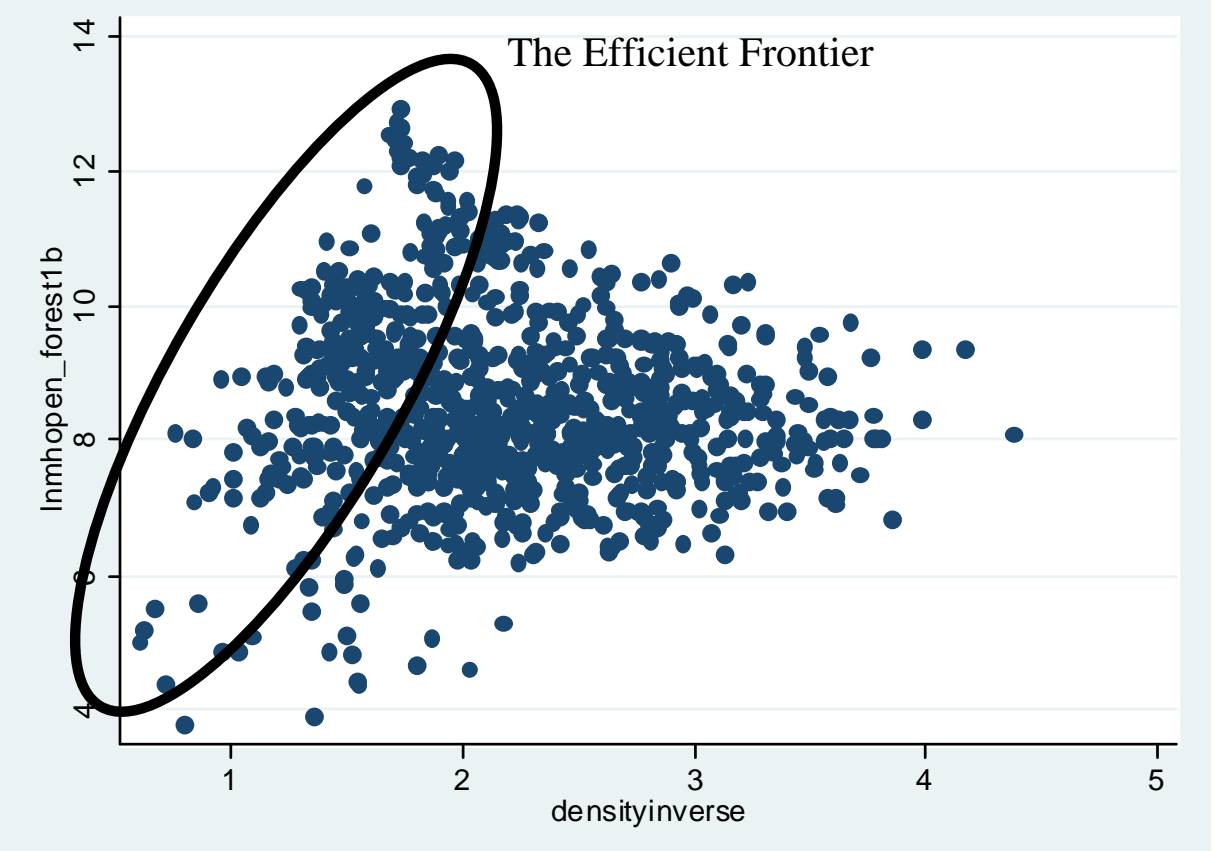

Source: Author's calculations using UN COMTRADE

Another tradeoff exists between the direct attractiveness of a product, PRODY, and distance. The products that are closest to the current export package may not be the most sophisticated, and therefore have the highest prices. Although higher-PRODY goods lead to greater subsequent growth according to Hausmann, Hwang and Rodrik (2006), goods that are further away imply greater difficult in adapting existing capabilities successfully. But as with the tradeoff between strategic value and distance, the tradeoff between direct value and distance carries with it an efficient frontier, shown below in Figure 21. 
Figure 21

South Africa's Open Forest, 2004: Proximity versus PRODY

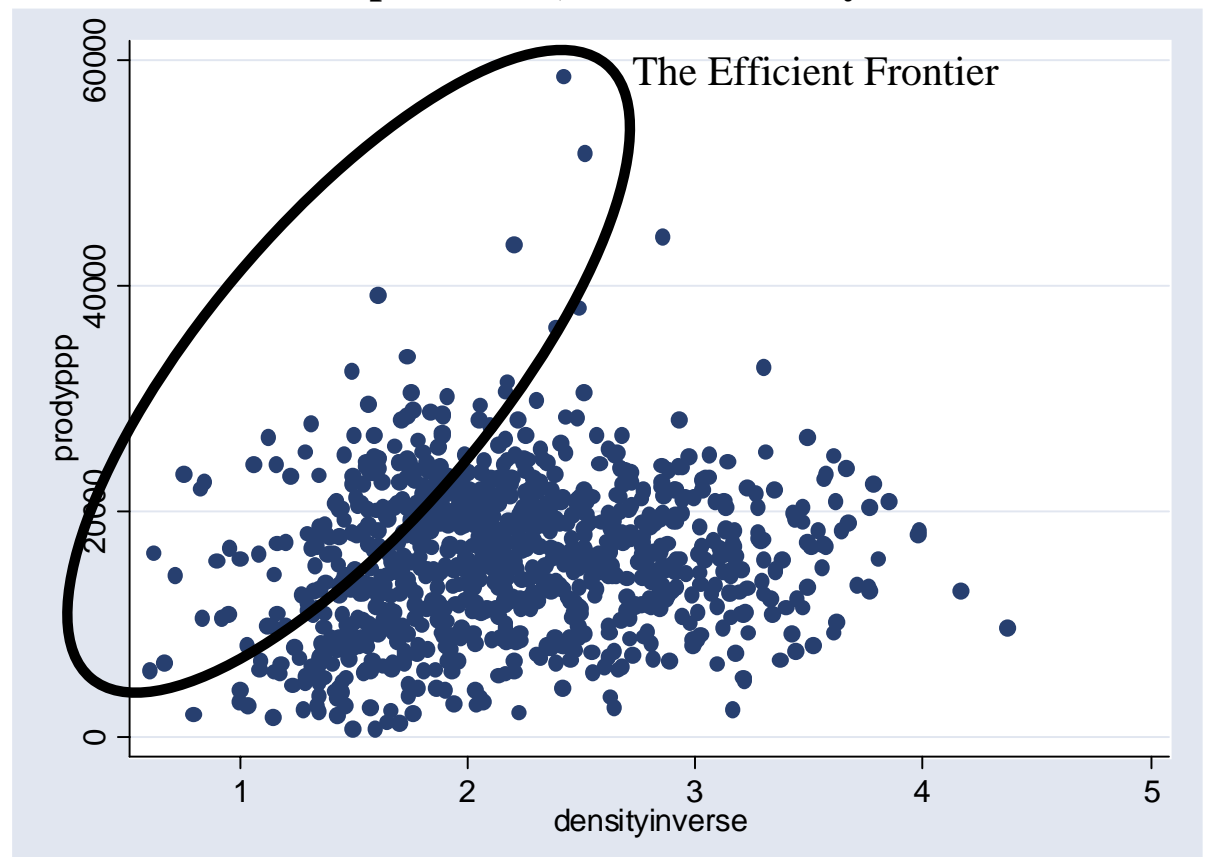

Source: Author's calculations using UN COMTRADE

When considering industrial strategy, these are three fundamental characteristics that can be used when prioritizing the provision of public goods and the resolution of coordination failures that are sector- or product-specific. In order to get a rough sense of what such a priority list would look like, we can combine these three objectives as follows. We first take the entire universe of goods not produced in South Africa as of 2004 as the HS 4digit level. Across all these goods we calculate the mean and standard deviation of PRODY, proximity, and strategic value. Each product is then scored on each dimension by subtracting the mean and dividing by the standard deviation from the actual value for that observation. Finally, these standardized scores are combined with alternative weighting functions.

We perform this analysis, take the top 100 scored products, and aggregate them to ISICr2 sectors in order to understand what products represent the best tradeoffs between these three goals, and also to determine how neatly this product list fits into sectoral divisions. This second point is rather important: if the attractive products from the point of view of industrial development neatly fit into one or two sectors, then a strong sectoral-focus to industrial strategy may be advisable. However, if the top 100 products are a rather diverse mix of sectors, then conceptualizing industrial strategy by sector may not be the best way to simplify the universe of potential production, as attractive products may be spread across a wide range of sectors, and many sectors would also include relatively unattractive products.

Figure 22 shows the results of this analysis under a balanced strategy with an equal weighting of $1 / 3$ for each of the three scores. Figure 22.A weights the products by 
unoccupied world market size (world exports in 2004 less South African exports in 2004), and Figure 22.B gives each product in the indicated sector equal weight.

\section{Figure 22}

\section{Balanced Strategy, World Trade Weighted}

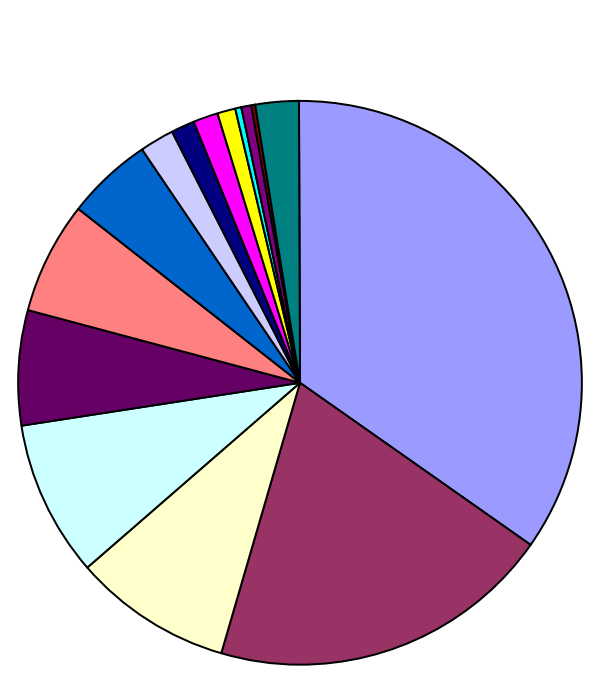

$\square$ Manufacture of office, computing and accounting machinery

$\square$ Manufacture of drugs and medicines

$\square$ Manufacture of special industrial machinery and equipment except metal and wood working machinery

$\square$ Machinery and equipment except electrical not elsewhere classified

- Manufacture of professional and scientific, and measuring and controlling equipment not elsewhere cl

$\square$ Manufacture of basic industrial chemicals except fertilizer

๑ Manufacture of metal and wood working machinery

$\square$ Slaughtering, preparing and preserving meat

- Manufacture of electrical industrial machinery and apparatus

๑ Manufacturing industries not elsewhere classified

$\square$ Manufacture of vegetable and animal oils and fats

$\square$ Manufacture of miscellaneous products of petroleum and coal

- Manufacture of electrical apparatus and supplies not elsewhere classified

— Agricultural and livestock production

๑ Other

Source: Author's calculations based on UN COMTRADE

Figure 22.B

\section{Low Hanging Fruit Strategy, World Trade Weighted}

$\square$ Manufacture of drugs and medicines

$\square$ Machinery and equipment except electrical not elsewhere classified

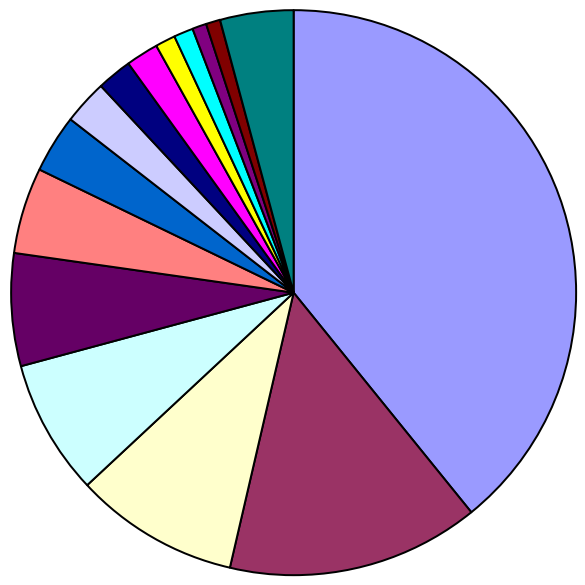

$\square$ Manufacture of special industrial machinery and equipment except metal and wood working machinery

$\square$ Manufacture of basic industrial chemicals except fertilizer

- Agricultural and livestock production

$\square$ Manufacture of vegetable and animal oils and fats

$\square$ Manufacture of dairy products

$\square$ Non-ferrous metal ore mining

- Manufacture of metal and wood working machinery

$\square$ Slaughtering, preparing and preserving meat

$\square$ Manufacture of fertilizers and pesticides

$\square$ Manufacture of cocoa, chocolate and sugar confectionery

$\square$ Manufacture of cement, lime and plaster

- Manufacture of plastic products not elsewhere classified

口 Other

Source: Author's calculations based on UN COMTRADE 
Figure 23.A and 23.B below repeat the same analysis, but with a different weighting function, placing a greater emphasis on the low-hanging fruit. This is accomplished with by placing a weight of .8 on proximity and a weight of .1 on strategic value and PRODY.

Figure 23.A

\section{Balanced Strategy, Product Count Weighted}

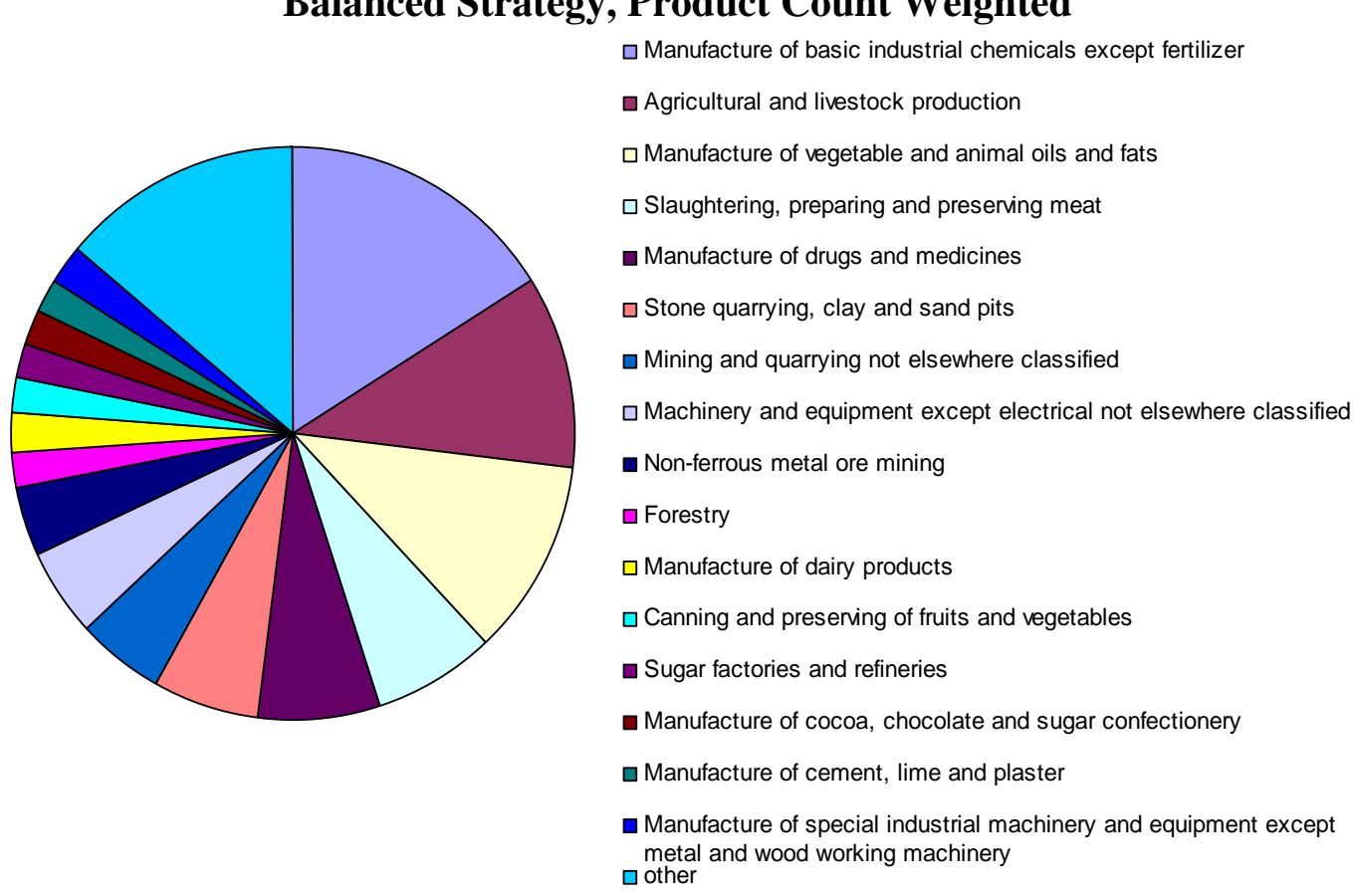

Source: Author's calculations based on UN COMTRADE

Figure 23.B: Low Hanging Fruit Strategy, Product Count Weighted

$\square$ Manufacture of basic industrial chemicals except fertilizer

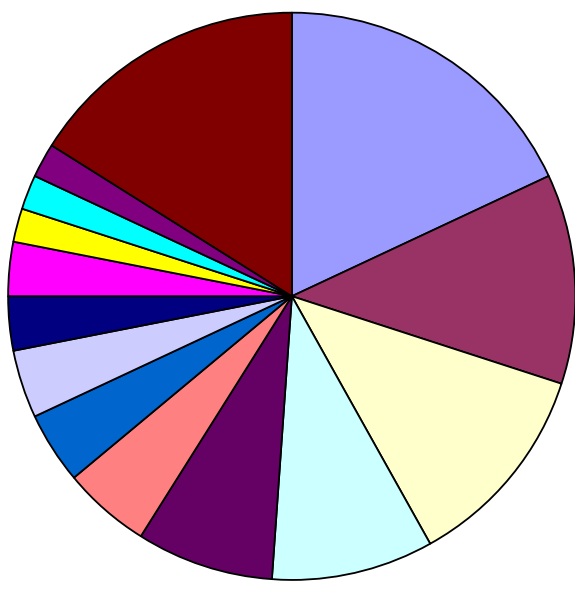

$\square$ Manufacture of metal and wood working machinery

$\square$ Manufacture of special industrial machinery and equipment except metal and wood working machinery

$\square$ Machinery and equipment except electrical not elsewhere classified

Manufacture of drugs and medicines

$\square$ Manufacture of professional and scientific, and measuring and

controlling equipment not elsewhere $\mathrm{cl}$

$\square$ Slaughtering, preparing and preserving meat

$\square$ Manufacture of office, computing and accounting machinery

- Agricultural and livestock production

$\square$ Iron and steel basic industries

$\square$ Non-ferrous metal ore mining

$\square$ Stone quarrying, clay and sand pits

Manufacture of vegetable and animal oils and fats

$\square$ Other

Source: Author’s calculations based on UN COMTRADE 
These figures reveal a rather heterogeneous mix of sectors. There are very diverse types of machinery, agricultural products, pharmaceutical products, and mining and processed commodities, in addition to a significant number of products that fall into other sectors.

Industrial strategy is further complicated by the other pressing goals in South Africa, relating to the labor market. South Africa has a large pool of underutilized unskilled labor, in addition to high levels of capital. We can use figures for intensity in capital and unskilled labor by 3-digit SIC category in TIPS and combine this with our open forest data to examine the tradeoffs. If we take the set of products not produced with comparative advantage as of 2004 and limit our attention to those with at least a 70\% unskilled labor share and capital labor ratio of 100 or more, we are left with the products shown in red in Figure 24 below.

Figure 24

South Africa’s Open Forest, 2004: Proximity versus Strategic Value

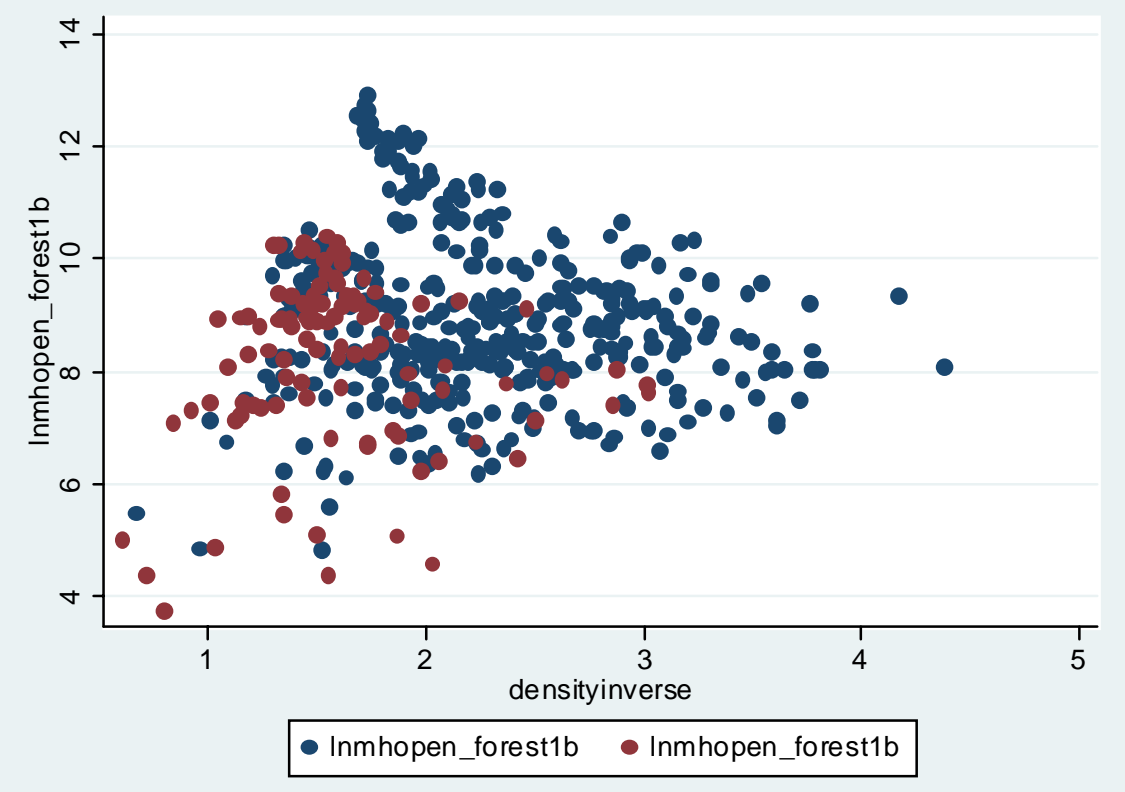

Products with at least $70 \%$ unskilled labor ratio and 100 capital/labor ration shown in red. Source: Author's calculations using UN COMTRADE and TIPS

These products essentially fall into two categories: agriculture food and animal products, and clothing and textiles ${ }^{3}$. But we can see from Figure 24 that some of these products that are attractive from a labor-absorption point of view are on the efficient frontier, while others are inside the efficient frontier. Comparing these two categories of products in terms of distance and strategic value, we see in this case that a sectoral view does show some meaningful differences: agriculture, animals, and food products are much nearer to

\footnotetext{
${ }^{3}$ Such a neat sectoral grouping is not unexpected, as even the three-digit SIC groupings from TIPS are or a relatively high aggregation (only 46 sectors, compared to 1400 in our export data).
} 
South Africa's current productive structure (Figure 25), and are also of a much higher strategic value for South Africa (Figure 26) when compared to clothing and textiles.

Figure 25

Average Distance from South Africa's Export Package, 2004

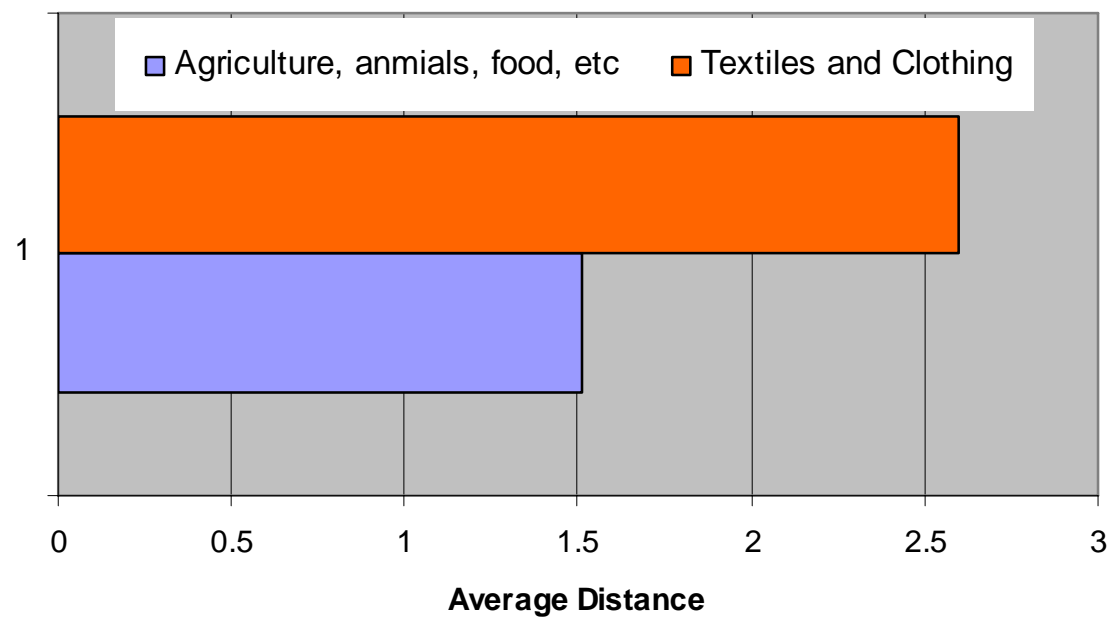

Source: Author's calculations using UN COMTRADE

Figure 26

Average Strategic Value for South Africa's future Structural Transformation, 2004

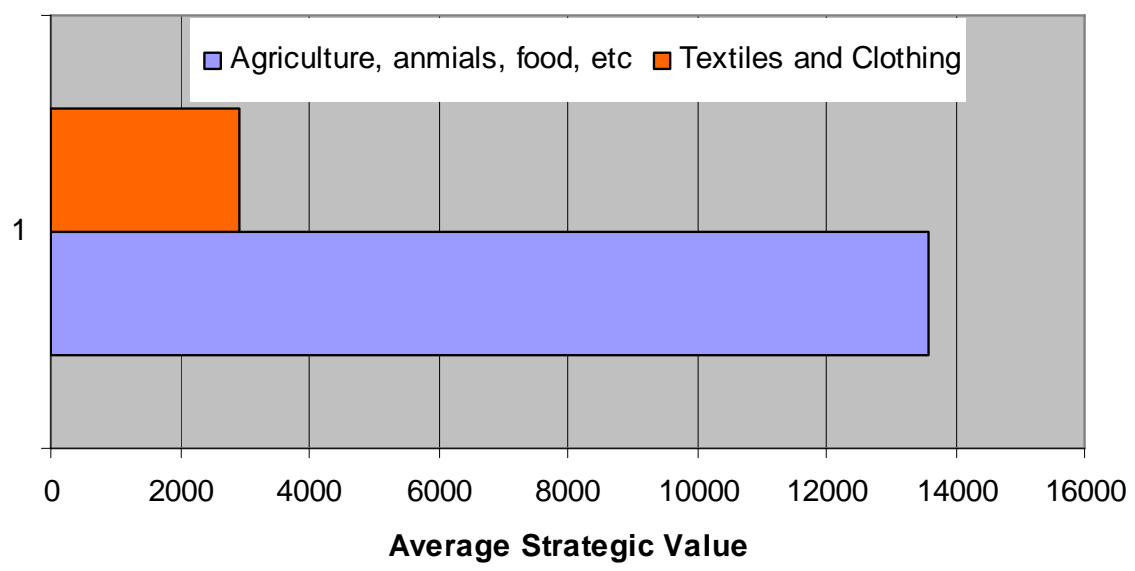

Source: Author's calculations using UN COMTRADE

This analysis suggests that a sectoral approach to South Africa's industrial strategy may offer some useful information. For example, while agriculture and clothing are both sectors that are intensive in unskilled labor and capital, the clothing sector is rather far away from South Africa's current productive structure, meaning that firms are less likely to successfully enter this industry even if authorities were to prioritize sector-specific institutional development and infrastructure. Furthermore, it is of a much lower strategic value, meaning that even if efforts to prioritize this sector were to succeed, they would 
not have much of a positive effect on future structural transformation, as the new, not pre-existing capabilities that would be acquired in the economy are of value to little else.

Yet, we also see that when considering the economic objectives achieved by successful penetration of various products, there are very attractive targets in a rather diverse set of sectors. This suggests that a sectoral-approach to South Africa's industrial strategy may discard some products of great value and prioritize others of little value. We return to this in the Section 5, but first move on to evaluate the DTI's current industrial strategy in the light of these tradeoffs. 


\section{Section 4: The DTI's Industrial Strategy}

The DTI's National Industrial Strategy identifies 14 priority sectors. ${ }^{4}$ The first point of note is that even though this strategy is prioritized in terms of sectors, the strategy is not highly focused at the product level, as 854 products out of a total of 1241 in the HS-4digit system are targeted. As discussed in Section 5, this broad focus is not necessarily a bad thing.

With almost $70 \%$ of export goods potentially targeted under this strategy, the first question is whether it is wise to omit the other $30 \%$ of products. Figure 27 shows where these omitted products lie in South Africa's open forest in terms of the distance/strategic value tradeoff. As can be seen, these omitted products are largely inside the efficient frontier, meaning that they are both far away from South Africa's current productive structure, and they offer little in terms of providing capabilities valuable for future structural transformation. That is, the omissions seem quite sensible.

Figure 27

\section{South Africa's Open Forest, 2004: Products not targeted in the DTI's Industrial} Strategy shown in green

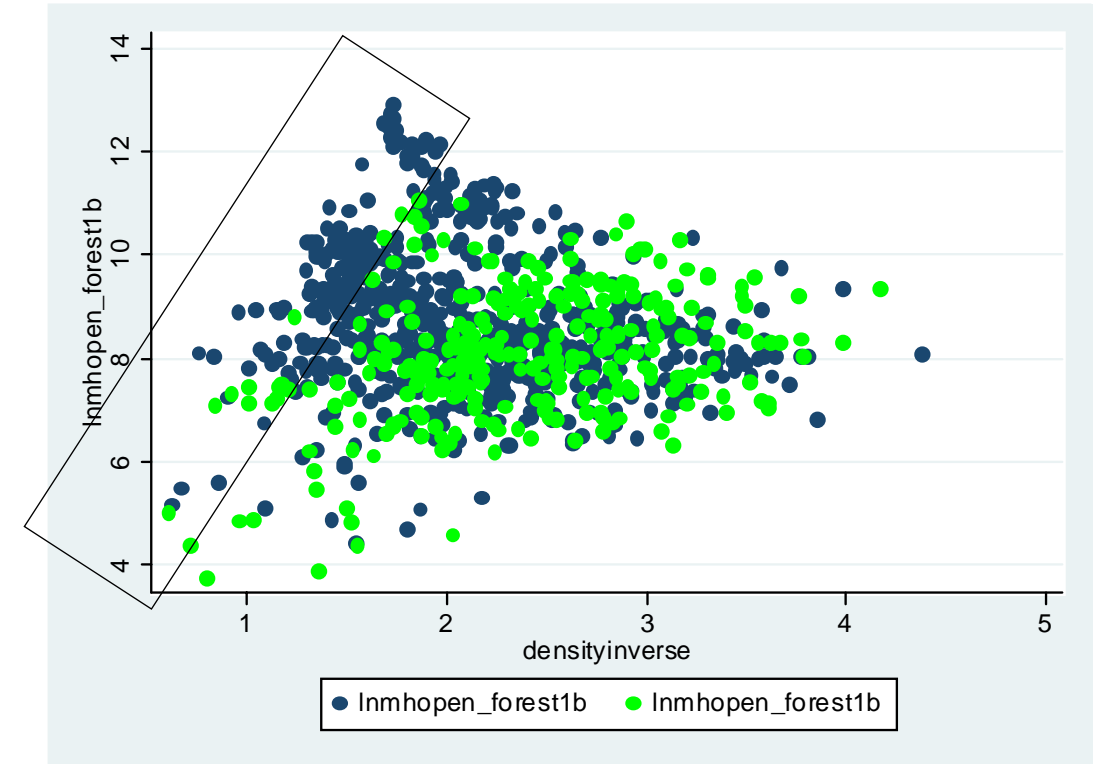

Source: Author's calculations based on UN COMTRADE

\footnotetext{
${ }^{4}$ We thank Nimrod Zalk of the DTI for providing us with a list of priority sectors and a correspondence between these sectors and individual products at the HS 4-digit level, which has made this analysis possible. A small group of products was listed both under plastics and under basic chemicals- these products were assigned to the plastics sector for this analysis. The 14 targeted sectors are energy, crafts, film \& television, biofuels, coke \& refined products, basic chemicals, other chemicals, clothing, textiles, metal fabrication, machinery \& equipment, plastics, agriculture, and aerospace. Energy, crafts, film \& television, and biofuels do not enter in our international trade data, and therefore can't be evaluated.
} 
Figures 28.A through 28.J show the equivalent map of open forest, with the targeted goods for each sector indicated in green. Note that because our area of interest is future structural transformation, we are only examining those goods for which South Africa has not yet achieved comparative advantage.

Figure 28.A

Agriculture

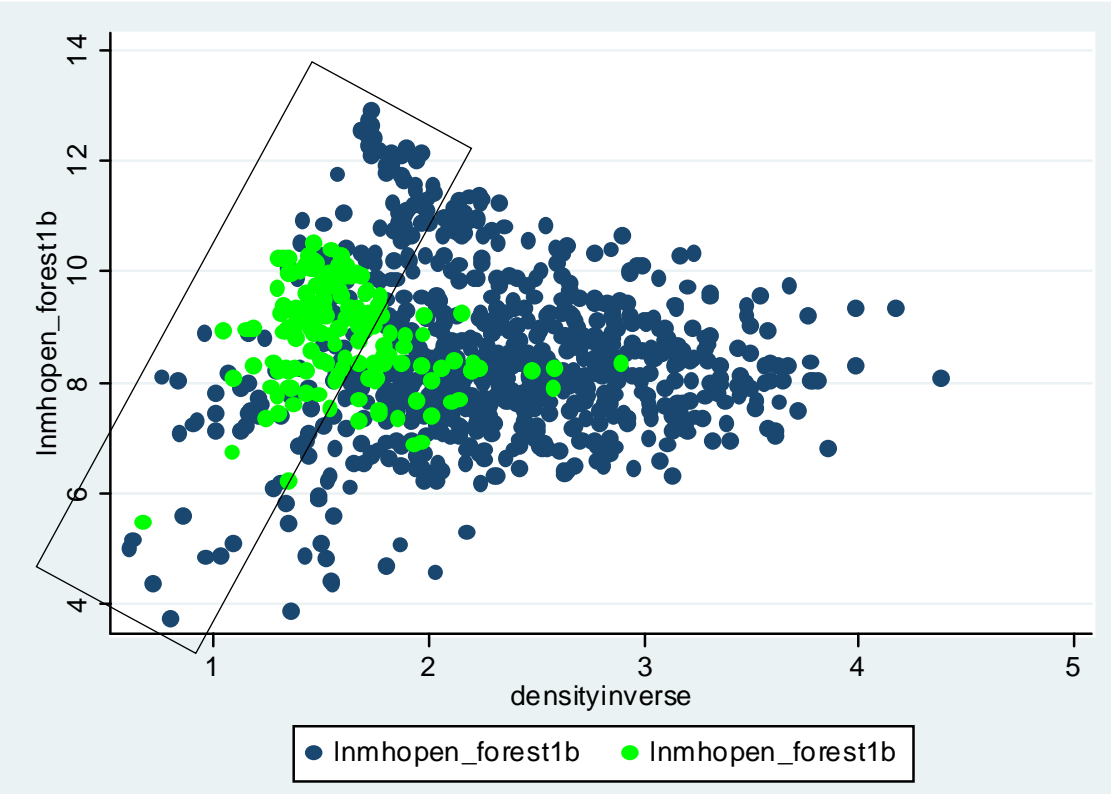

Source: Author's calculations based on UN COMTRADE

Figure 28.B

Machinery

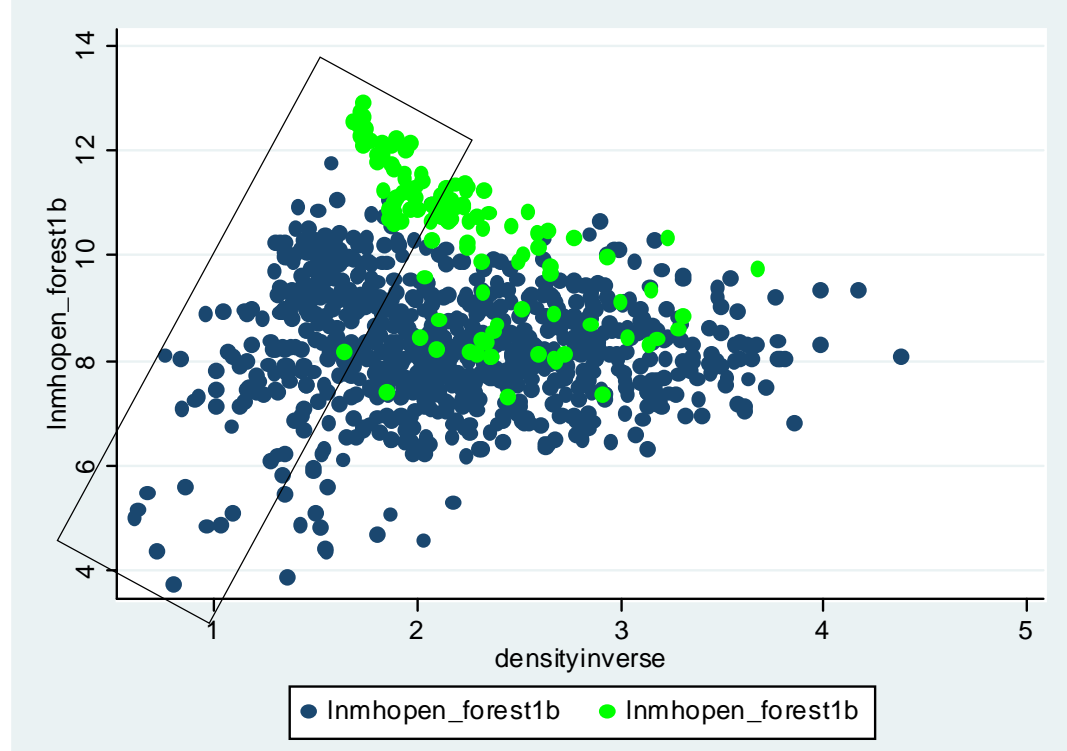

Source: Author's calculations based on UN COMTRADE 
Figure 28.C

Coke \& Refined Products

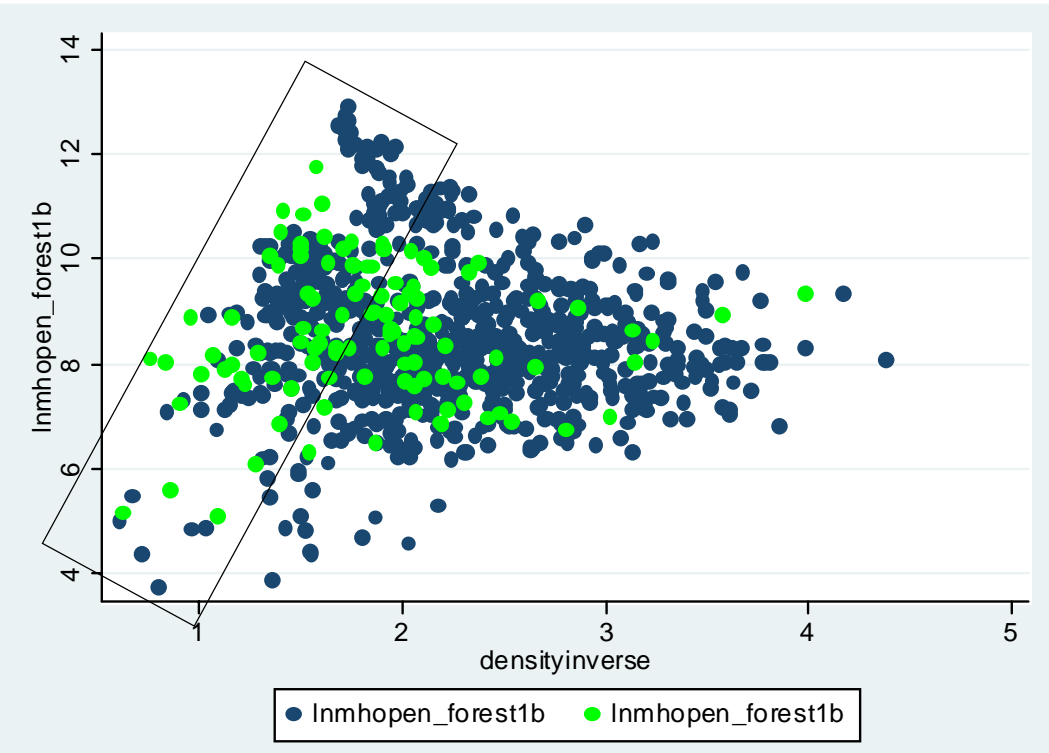

Source: Author's calculations based on UN COMTRADE

Figure 28.D

Basic Chemicals

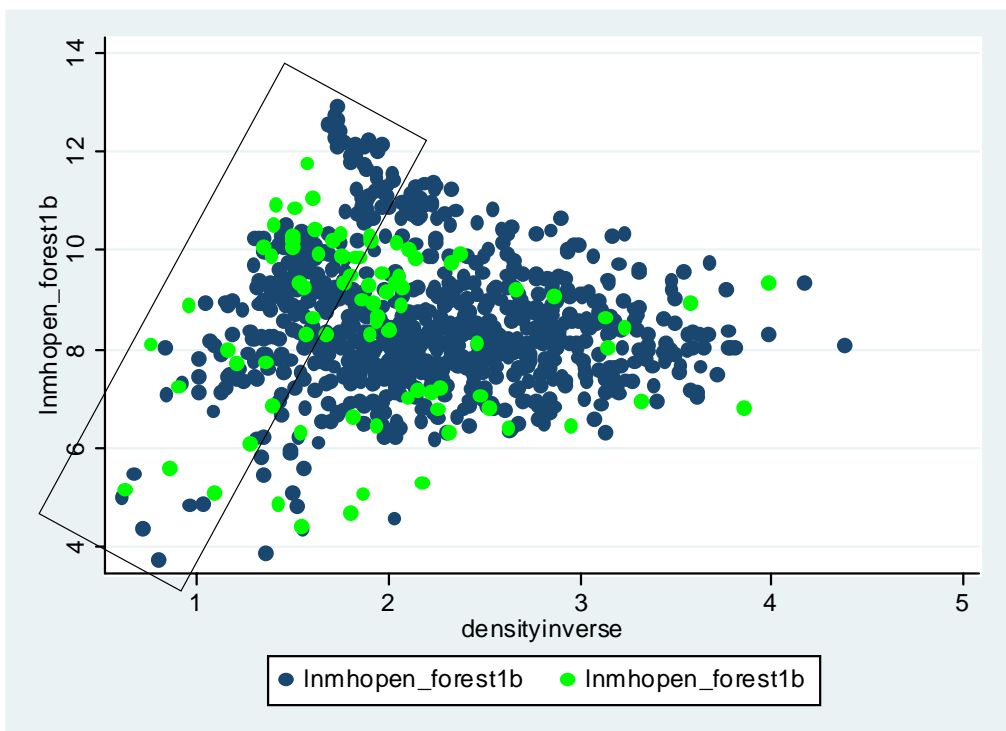

Source: Author's calculations based on UN COMTRADE 
Figure 28.E

Other Chemicals

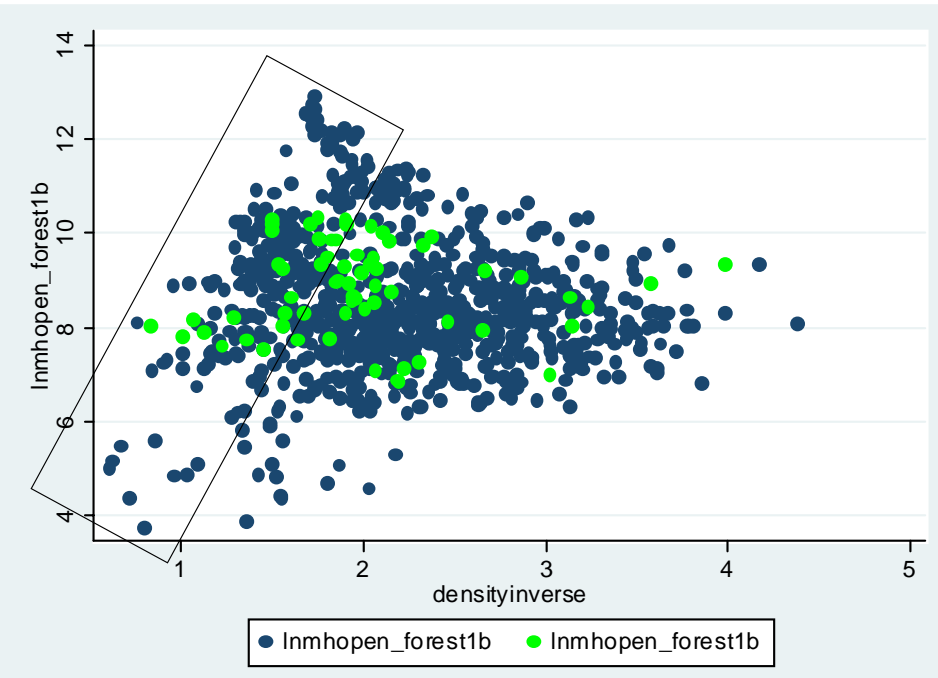

Source: Author's calculations based on UN COMTRADE

Figure 28.F

Metal Fabrication

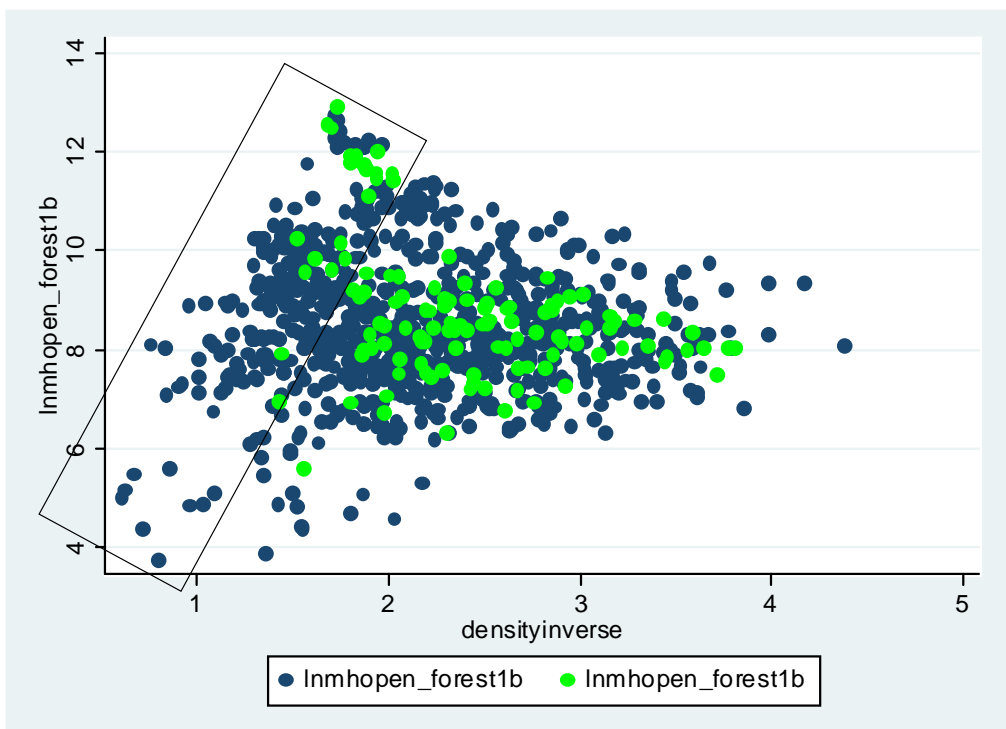

Source: Author's calculations based on UN COMTRADE 


\section{Figure 28.G}

Plastics

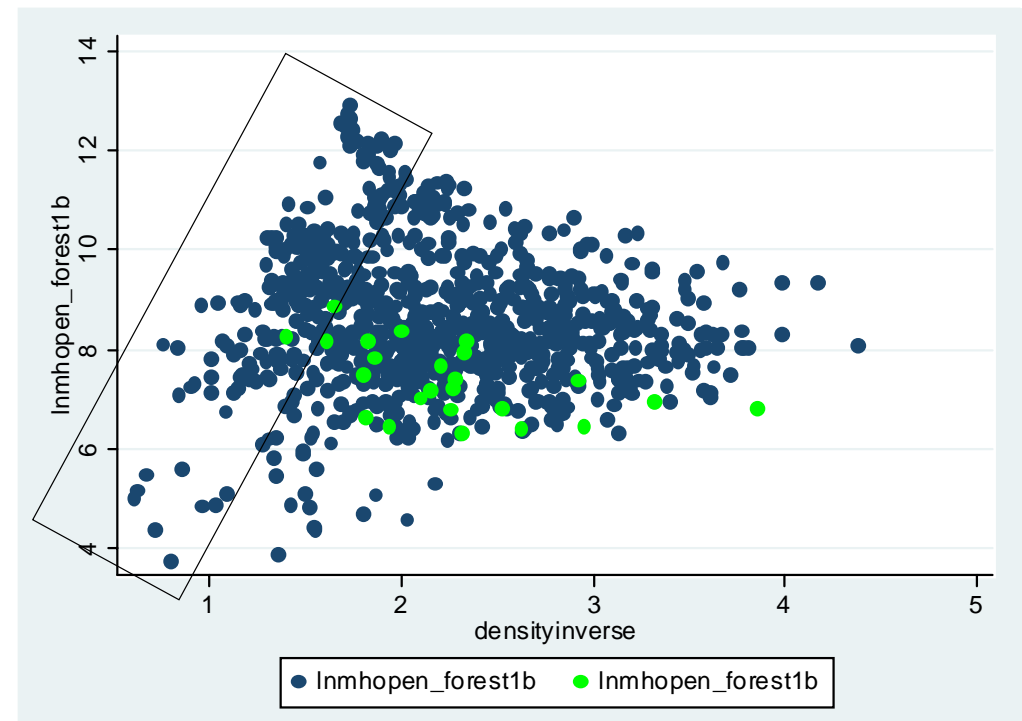

Source: Author's calculations based on UN COMTRADE

\section{Figure 28.H}

Textiles

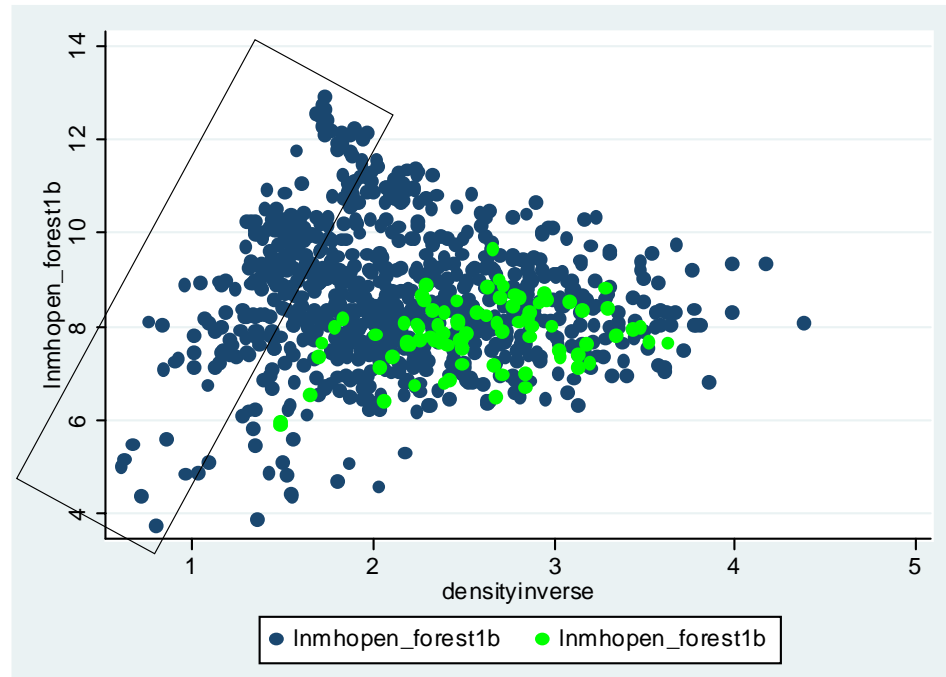

Source: Author's calculations based on UN COMTRADE 


\section{Figure 28.I}

\section{Clothing}

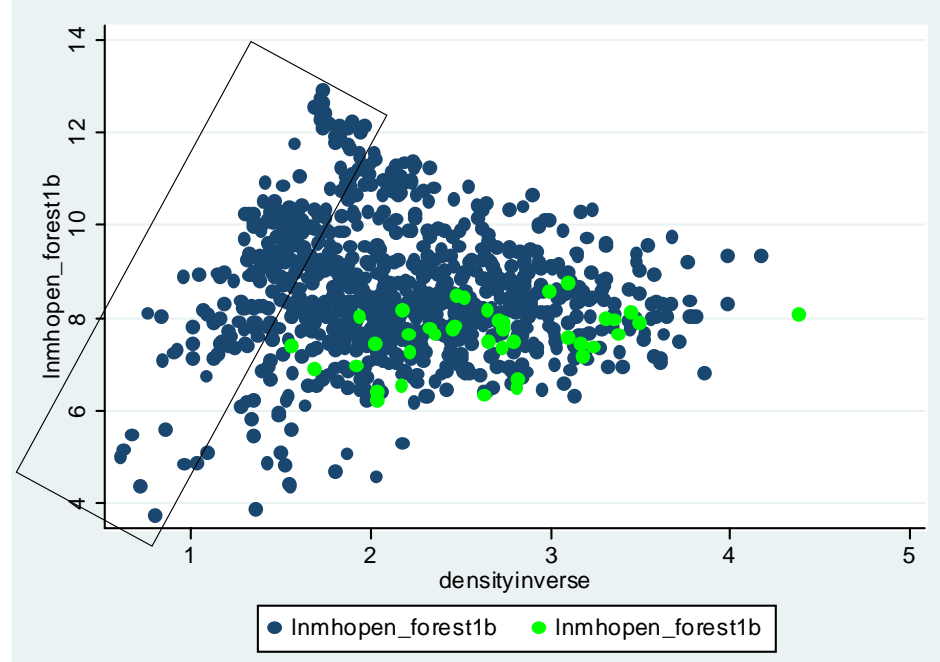

Source: Author's calculations based on UN COMTRADE

Figure 28.J

Aerospace

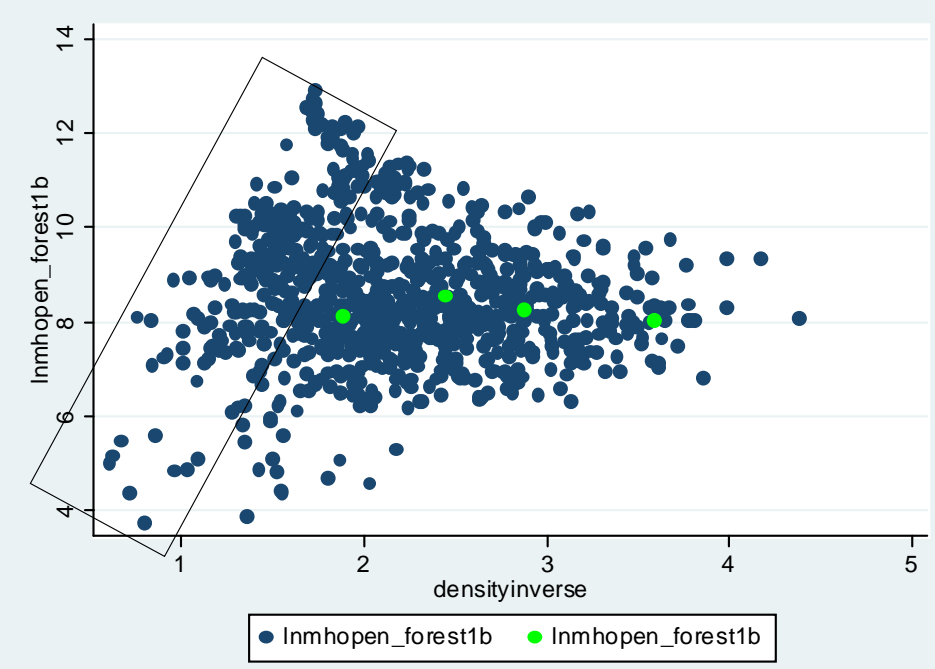

Source: Author's calculations based on UN COMTRADE

While there is significant heterogeneity among the products in each sector, certain generalizations emerge. Some sectors, such as agriculture, lie largely on the efficient frontier. Others, such as machinery, coke \& refined products, chemicals, metal fabrication, and plastics are comprised of some frontier goods and some unattractive goods. Finally, sectors such as textiles, clothing, and aerospace are largely inside the efficient frontier, representing neither low hanging fruit nor strategically valuable products. Simultaneously, and as discussed in Section 3, the efficient frontier is rather diverse in that it includes products from most sectors. 
In addition to the goals of strategic value and proximity, both the level of sophistication (PRODY) and the share of unskilled labor are goals of South Africa's Industrial Strategy. Using the same standardization and scoring methodology as in Section 3, these goals can be combined into one overall score. We use four different weighting functions: a balanced strategy (a weight of .25 on each of PRODY, proximity, strategic value, and unskilled labor share), a low-hanging fruit strategy (.7 weight on proximity, .1 on the rest), a labor-absorbing strategy (.7 weight on unskilled labor share, .1 on the rest), and an externality generating strategy (.7 weight on strategic value, .1 on the rest). The results based on the average score across all products in the sector targeted by DTI, are shown below in Tables 2.A through 2.D.

Table 2.A

\begin{tabular}{lc}
\multicolumn{1}{c}{$\begin{array}{c}\text { Balanced Strategy, Sector Average } \\
\text { Sector }\end{array}$} \\
machinery & 0.24 \\
agriculture & 0.19 \\
basic chemicals & 0.11 \\
plastics & 0.02 \\
coke and refined products & 0.02 \\
metal fabrication & -0.04 \\
textiles & -0.07 \\
clothing & -0.20 \\
aerospace & -0.29
\end{tabular}

Source: Author's calculations based on UN COMTRADE

Table 2.B

\begin{tabular}{|c|c|}
\hline \multicolumn{2}{|c|}{ Low Hanging Fruit Strategy, Sector Average } \\
\hline Sector & Score \\
\hline agriculture & 0.68 \\
\hline coke and refined products & 0.32 \\
\hline basic chemicals & 0.07 \\
\hline plastics & -0.03 \\
\hline machinery & -0.06 \\
\hline metal fabrication & -0.22 \\
\hline textiles & -0.35 \\
\hline aerospace & -0.42 \\
\hline clothing & -0.42 \\
\hline
\end{tabular}

Source: Author's calculations based on UN COMTRADE 
Table 2.C

\begin{tabular}{|c|c|}
\hline Sector & Score \\
\hline clothing & 0.64 \\
\hline textiles & 0.50 \\
\hline agriculture & 0.37 \\
\hline basic chemicals & 0.35 \\
\hline plastics & -0.08 \\
\hline metal fabrication & -0.21 \\
\hline machinery & -0.26 \\
\hline coke and refined products & -0.50 \\
\hline aerospace & -0.55 \\
\hline
\end{tabular}

Source: Author's calculations based on UN COMTRADE

Table 2.D

$\begin{array}{lc}\begin{array}{c}\text { Externality Generation Strategy, } \\ \text { Sector }\end{array} & \begin{array}{c}\text { Sector Average } \\ \text { Score }\end{array} \\ \text { machinery } & 0.80 \\ \text { metal fabrication } & 0.13 \\ \text { agriculture } & 0.01 \\ \text { coke and refined products } & -0.05 \\ \text { basic chemicals } & -0.19 \\ \text { plastics } & -0.19 \\ \text { textiles } & -0.22 \\ \text { clothing } & -0.28 \\ \text { aerospace } & -0.29\end{array}$

Source: Author's calculations based on UN COMTRADE

The averaging of scores across all products in the sector may not be appropriate for two reasons. First, it is possible that more refined product targeting within each sector be undertaken, using this data. Second, and more likely, private actors in these sectors can be expected to optimize along some of these dimensions, and therefore naturally would select the higher-scored products within each sector. As motivated in Hausmann \& Klinger (2006), both distance and PRODY will be at least partially internalized by the firm, as would the benefits of using the vast supplies of unskilled labor. Strategic value is the dimension that private actors are least likely to internalize, given that many capabilities are public goods, and it is reasonable to expect that the firms taking secondorder steps in the process of structural transformation will not be the same as those making the first steps.

To allow for this, we repeat the analysis above, but only take the average across products with a score above the within-sector median, meaning that we only consider the most attractive half of products in each sector. The results are shown below in Tables 3.A through 3.D. 


\begin{tabular}{lc}
\multicolumn{2}{c}{ Table 3.A } \\
Balanced Strategy, Rationalized \\
Sector & Sector Average \\
machinery & 0.64 \\
agriculture & 0.53 \\
coke and refined products & 0.34 \\
basic chemicals & 0.33 \\
metal fabrication & 0.30 \\
plastics & 0.26 \\
textiles & 0.15 \\
clothing & -0.04 \\
aerospace & -0.11
\end{tabular}

Source: Author's calculations based on UN COMTRADE

Table 3.B

Low Hanging Fruit Strategy, Rationalized Sector Average

\begin{tabular}{lc}
\multicolumn{1}{c}{ Sector } & Score \\
agriculture & 1.07 \\
coke and refined products & 0.96 \\
basic chemicals & 0.58 \\
machinery & 0.35 \\
plastics & 0.33 \\
metal fabrication & 0.21 \\
textiles & -0.06 \\
aerospace & -0.12 \\
clothing & -0.14
\end{tabular}

Source: Author's calculations based on UN COMTRADE

Table 3.C

Labor Absorbing Strategy, Rationalized Sector Average

\begin{tabular}{lc}
\multicolumn{1}{c}{ Sector } & Score \\
agriculture & 1.15 \\
clothing & 0.82 \\
textiles & 0.80 \\
basic chemicals & 0.63 \\
plastics & 0.26 \\
metal fabrication & 0.04 \\
machinery & 0.02 \\
coke and refined products & -0.24 \\
aerospace & -0.47
\end{tabular}

Source: Author's calculations based on UN COMTRADE 


\begin{tabular}{lc}
\multicolumn{2}{c}{ Table 3.D } \\
Externality Generation Strategy, Rationalized Sector Average \\
\multicolumn{1}{c}{ Sector } & Score \\
machinery & 1.68 \\
metal fabrication & 0.59 \\
agriculture & 0.21 \\
coke and refined products & 0.19 \\
plastics & -0.09 \\
basic chemicals & -0.10 \\
textiles & -0.11 \\
clothing & -0.21 \\
aerospace & -0.23
\end{tabular}

Source: Author's calculations based on UN COMTRADE

We see that, consistent with the findings in Section 3, the clothing and textiles sector scores quite low unless an extremely high weight is placed on unskilled labor intensity, and even in that case these sectors score below agriculture. In addition, the aerospace sector consistently scores quite low. Note that we are only considering products in which South Africa has not yet achieved comparative advantage, so it is possible that from the point of view of expanding existing export successes, aerospace may be an attractive target. However, from the point of view of stimulating future structural transformation, it is much less attractive than sectors like agriculture, machinery, basic chemicals, and refined products. These high-potential sectors are discussed in the following section, along with more general policy implications of this analysis. 


\section{Section 5: Policy Implications}

\section{General Policy Conclusions}

What policy implications emerge from our analysis? In principle, the ideal approach would imply the adoption of a sector-neutral promotion strategy that is concentrated on overcoming market and government failures, wherever they may be, and would thus not choose specific sectors. There are many reasons why this is clearly a superior strategy. First of all, as the analysis above has shown, the efficient frontier is composed of products belonging to quite a few sectors. Choosing too few sectors may condemn good opportunities to oblivion. Moreover, within each sector there is an enormous variation of potential payoffs, given that each sector contains products that are at very different distances, have varying intrinsic values (PRODYs) and very different strategic value. Having a treatment that parses the problem by sector may stimulate the good and the not so good within the chosen sectors while leaving many other potential good products out.

Hence, picking sectors should not be the preferred approach. It is true that, as Isaiah Berlin said, "we are doomed to choose and every choice may entail an irreparable loss". Hence, we should avoid choosing as much as possible but not refrain from choosing when we are doomed to it. But it is important not to choose when an alternative option is open.

The government is condemned to choose because economic activity has many complementary inputs which are provided publicly, and the government may not be able to identify and provide them all, at least instentaneously. Activities require rules, regulations and assets which are quite specific to each activity. These include inter alia infrastructure, forms of property, regulations, labor training, information provision, research and development, etc. Identifying what is required and providing it is not without cost in terms of money and administrative capability and hence not all needs will be taken care of. But ideally, choices should be made in the context of a policy process that identifies the opportunities and the private agents to exploit them as well as the obstacles that need to be removed.

There are forms of intervention where the government adopts a general policy and the economic agents select themselves into programs. This has the advantage of allowing the identification to be made with more information and to have the society self-organize around the opportunities it identifies. This may help overcome an important problem of ex ante selection: choosing a counter-party and forcing it to agree on a course of action may not select the ideal path. If the group is too broad relative to the specificity of the public good that needs to be identified and provided, say a particular road, the majority of the group will not agree to it because it does not stand to benefit from it, and may prefer instead a tax holiday, even though this second alternative may not be the highest return intervention. A policy based on self-selection may end up getting into the table the whole gamut between individual promoters, sets of firms or established trade associations. 
While we understand the need to have a sectoral dimension to the policy, we argue that in any case, the government should institute a "general window" based on the principle of self-selection by interested parties. This window would receive suggestions for intervention or program development in areas where its intervention is required. The government should have principles about what it is willing or not to do and how it will assess its intervention. We would propose the following principles in order to assure that the self-selection process is efficient and legitimate vis a vis the rest of society:

- Interventions should have the effect of increasing the real productivity of the activities proposed, not to compensate them financially for their lack of productivity

- Interventions should require from the government a role which is appropriate to it because it involves activities of sectors that are under its control, whether it be infrastructure, labor training, education, research and development, regulations and laws.

- Activities should involve exportables because these are scalable and because they do not involve choosing one supplier over another in the domestic market

- Requests for intervention should be public knowledge, i.e. should be posted on the DTI's website

- A technical secretariat will evaluate the interventions based on their social benefits and this evaluation should also be public knowledge.

- An ad hoc group should be formed in order to manage the program and monitor the engagements and commitments undertaken by both the private and the public sector

- An ex post evaluation should be planned from the beginning and should be published at an appropriate and predetermined date

- When possible, each intervention should be designed as broadly as possible to benefit not only the promoting group but other potential participants as well.

Such an open architecture has the advantage of allowing new ideas and opportunities to arise, even if the government does not identify them first and may evolve more naturally with opportunities over the long run. It may also save on administrative resources as the same staff may get involved in multiple initiatives.

\section{Sector-Specific Conclusions}

Having said this, there are some sector specific themes that emerge from our analysis. There are activities which appear to be in South Africa's efficient frontier and others seem to be farther away. There are four activities which appear to be very interesting: agriculture, machinery and equipment, pharmaceuticals and other chemicals. Other activities, such as textiles and apparel appear to be less interesting because they seem to be farther away and to have less strategic value.

An important caveat is that our analysis has used only data on goods and not on services. There may be important emerging opportunities in this field, such as business process outsourcing, aeronautic services, and tourism, which were excluded from our analysis for 
lack of data. But this should not be held against these activities. Instead, it is a limitation of our approach.

\section{Agriculture}

As expressed by Alan Hirsh (2005), agriculture faces limitations based on distance to market, rainfall and a history of inefficient and abusive property rights ${ }^{5}$. The amount of arable land per capita has been falling, the sector has been shedding labor and labor productivity has been on the rise but is constitutes only one third of the national average (Figures 29, 30, 31 and 32).

Figure 29

Arable Land per capita, South Africa

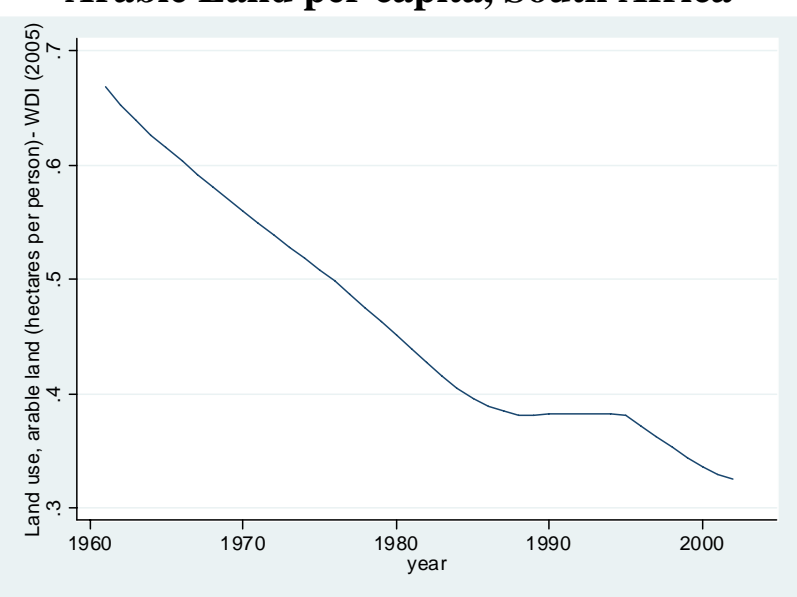

Source: World Bank WDI

\footnotetext{
${ }^{5}$ What about agriculture? Could it provide jobs and exports on which to base a new round of growth? One limitation on the use of agriculture as a source of growth is the small supply of arable land. Only $10 \%$ of South Africa receives more that 750 millimetres of rain per year. Much of the country is desert or semi-desert, and variations of rainfall are severe enough to result in frequent drought cycles. Indeed, variations in agricultural output can push the GDP growth rate up or down by as much as $1.5 \%$. Agriculture's contribution to GDP varies, averaging around $4 \%$. The combined contribution of agriculture, fish and timber to total South African exports declined from 19\% in 1957 to 5\% in 1985 (Cassim et al. 2003; Holden 1990). A second limitation is the fact that much agricultural land is owned by large landowners who are white and undercapitalised and do not have incentives to increase employment or output. Productivity and yield growth in the agricultural sector ran aground after the early 1970s, after years of lavish government support for farm investments. The land reform programme, intended to return a significant proportion of land to black people, started slowly in the agricultural sector. Though it has accelerated since 1999, the link between land reform and agricultural development remains fairly weak. There are undoubtedly opportunities for agricultural expansion in high-value products such as wine, berries, fruits, nuts, and processed agricultural products, but South Africa's distance from major markets has been a drawback."

"In short, while South Africa has several competitive agricultural products, some of which will contribute to growth and employment creation in the future, domestic climatic constraints and world market conditions mean that agriculture can never be a complete answer to South Africa's growth and employment challenges. This was evident to policy makers in the early 1990s." (Hirsh 2005)
} 
Figure 30

Agricultural Employment, South Africa

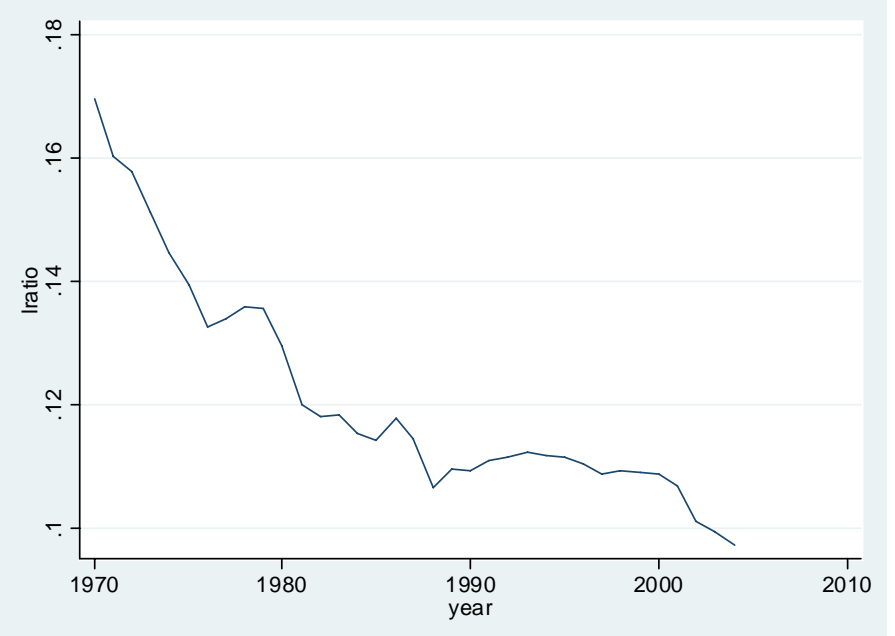

Source: World Bank WDI

Figure 31

Agricultural Value Added Per Worker, South Africa

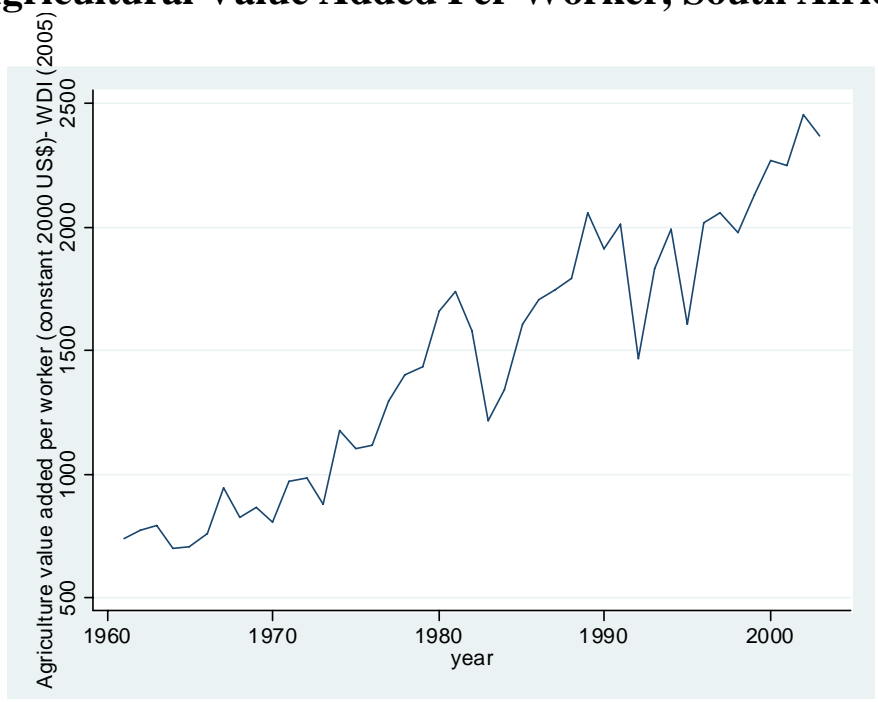

Source: World Bank WDI 
Figure 32

Agricultural VA Per Worker over National Average VA Per Worker, South Africa

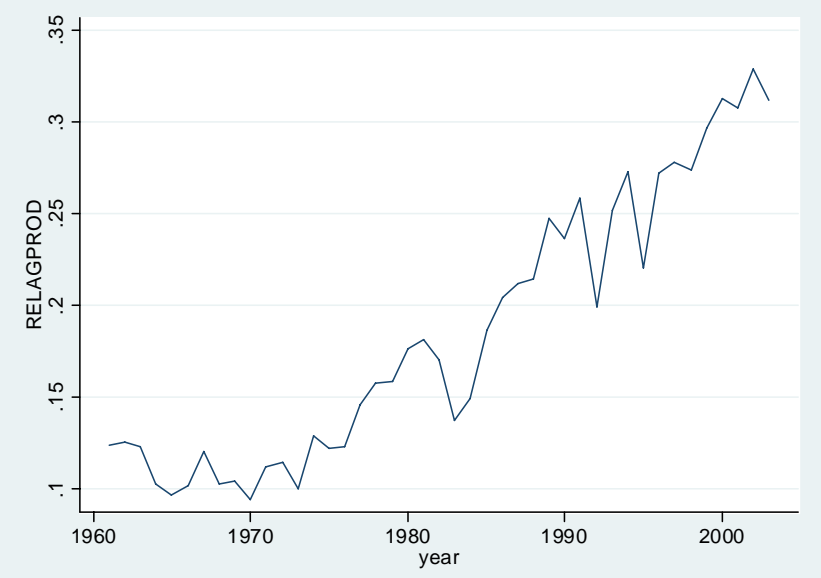

Source: World Bank WDI

However, Figure 33 below presents a scatter plot of value added per worker in agriculture vs. employment per hectare. The international variation across the world is enormous so the graph is presented in logarithmic terms. The graph shows that there are plenty of countries that either generate much more output for the same amount of employment per hectare, or much more employment for the same amount of value added per worker. This is a wake up call for the yet unexploited potential of a more ambitious strategy in agriculture. It is a sector that can exploit South Africa's good access to capital and ample unskilled labor. Moreover, its limited rainfall and dry lands suggests possibilities for the kind of modern agricultural successes seen recently in Israel, Egypt or Peru.

Figure 33

\section{Value added per worker vs. employment per hectare in agriculture, worldwide}

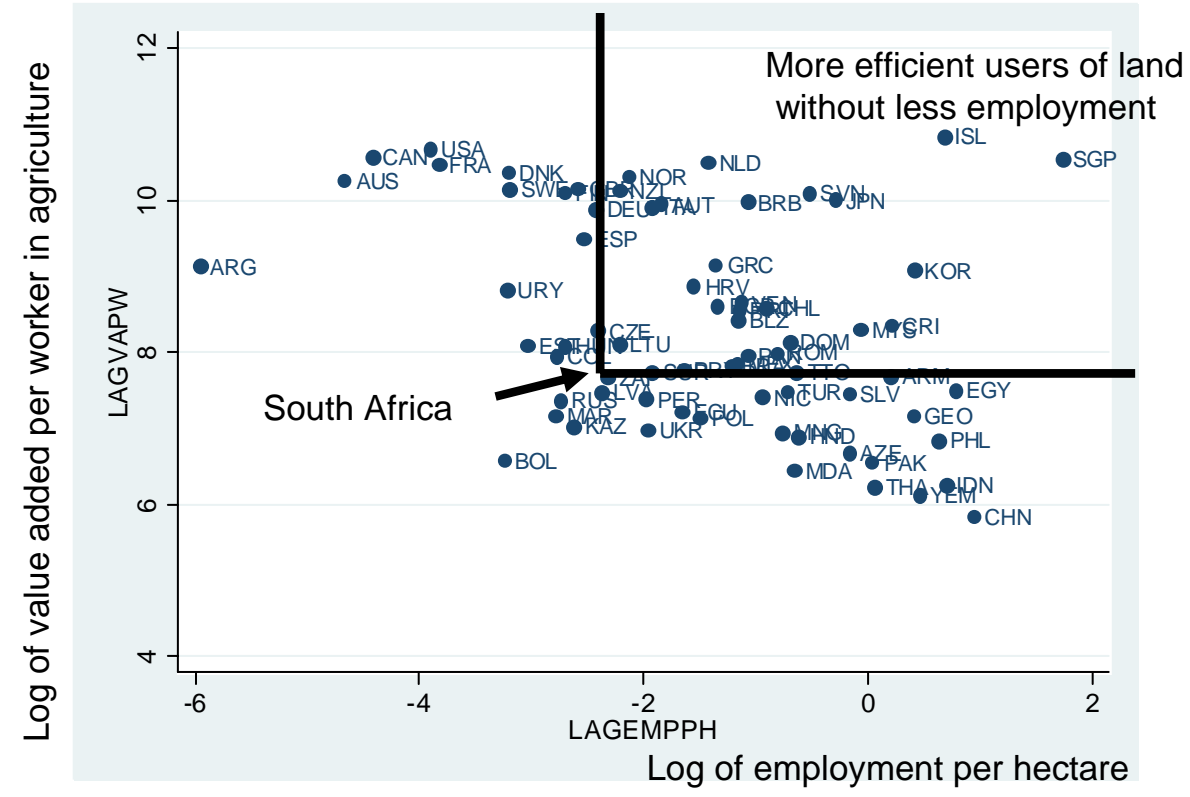

Source: World Development Indicators (2005) 


\section{Machinery and Equipment}

Machinery represents one of the densest parts of the product space. Once a country develops comparative advantage in these activities it can redeploy them to many other uses. Moreover, the world market is large and growing. South Africa already has a presence in the sector through its auto industry, other transportation equipment as well as professional and scientific equipment. This means that compared to other countries, the distance to this part of the product space is not that large for South Africa. Therefore a strategy to develop acquired comparative advantage in these activities may be warranted.

It is impossible to know ex ante what interventions may be needed to promote the sector so the policy process must be able to identify these. However, it would seem reasonable to assume that infrastructure, labor training, university efforts in mechanical, electrical and metal-mechanical engineering and R\&D are likely to be involved.

There is in addition a case to be made using government procurement. As argued in the Industrial Policy White Paper, the public investment expansion planned in ASGI-SA may allow the use of the government procurement strategy as an instrument for the promotion of the sector. This is made possible legally be the fact that South Africa did not sign the WTO Government Procurement Code. However, it is critical that the exercise of this discretion not be used in an inward-looking mode in order to lower the import content of the public investment program. The idea is to subsidize the industry-level learning by doing by creating a domestic supply that can become a new export activity once the ASGI-SA investments are rolled back. Therefore, the export plans of the local suppliers should be taken into consideration when qualifying domestic suppliers.

\section{Pharmaceuticals}

In economic terms, pharmaceuticals appear as a huge and rapidly growing global market. The recovery of growth in Africa and the emphasis of donors on health have created also a growing regional market. Moreover, there are significant specificities in the regional market due to the prevalence of tropical diseases and HIV-AIDS. Finally, there is very large donor interest in promoting the research and development of drugs for African diseases, as exemplified by the Bill and Melinda Gates Foundation.

South Africa already has some presence in the sector with some successful exporters of generic drugs. It would appear that some of the conditions needed to succeed in this field are present but the sector is very intensive in $R \& D$ and other regulations and hence an active involvement may allow the elimination of potential bottlenecks.

\section{Chemicals}

Chemicals are also in a very dense part of the product space with high PRODY and large strategic value. The country has a presence in the sector mainly through SASOL. The sector is also very intensive in $\mathrm{R} \& \mathrm{D}$ and intellectual property rights so that an inadequate provision of these inputs may be a problem. Moreover, the fact that SASOL is stateowned may have limited the diffusion of the activity beyond its core. 
This suggests that SASOL may try to diversify into new areas by promoting and attracting joint ventures in other fields.

\section{The role of foreign investment}

Greenfield foreign investment may be key to accelerate the process of structural transformation. An active investment promotion entity may be an important element of the strategy. While a general investment promotion policy may be needed - for both foreign and domestic agents - a strategy to raise the presence and visibility of the South Africa in the eyes of foreign corporations may be useful. Whether in agriculture, pharmaceuticals, machinery, chemicals, business process outsourcing, tourism or any other area considered potentially important, a well designed strategy to attract the interest of major global players may be an important complement to a development strategy. 


\section{References}

Arrow, K. 1962. "The economic implications of learning by doing" Review of Economic Studies 29(3): 155 - 173.

Barabasi, A., R. Hausmann, C. Hidalgo \& B. Klinger. Untitled. Forthcoming.

Bardhan, P. 1970. Economic growth, development, and foreign trade. Wiley-Interscience, New York.

Ferranti, D., G. Perry, D. Lederman \& W. Maloney. 2002. "From Natural Resources to the Knowledge Economy” World Bank, Washington, DC.

Feenstra, R. R. Lipsey, H. Deng, A. Ma and H. Mo. 2005. "World Trade Flows: 19622000” NBER working paper 11040. National Bureau of Economic Research, Cambridge MA.

Hausmann, R. J. Hwang and D. Rodrik. 2006. "What you export matters" NBER Working paper 11905. National Bureau of Economic Research, Cambridge MA.

Hausmann, R., \& B. Klinger. 2006. "Structural transformation and patterns of comparative advantage in the product space.” Mimeo, Harvard University.

Hausmann, R. and D. Rodrik. 2003. “Economic development as self-discovery.” Journal of Development Economics. 72: 603-633.

Hirsh, A. 2005. Season of hope: economic reform under Mandela and Mbeki. University of KwaZulu-Natal Press, Scottsville, South Africa.

Jaffe, A. 1986. “Technological opportunity and spillovers of R\&D: evidence from firm's patents, profits, and market value” American Economic Review 76(5): 984-1001.

Leamer, Edward E. 1984. Sources of Comparative Advantage: Theory and Evidence. Cambridge MA: The MIT Press. 